\title{
Prototype Demonstration of the
} Integration of a Gibbs Energy Minimizer with TRANSFORM for Molten Salt

\section{Reactor Mass Accountancy Studies}

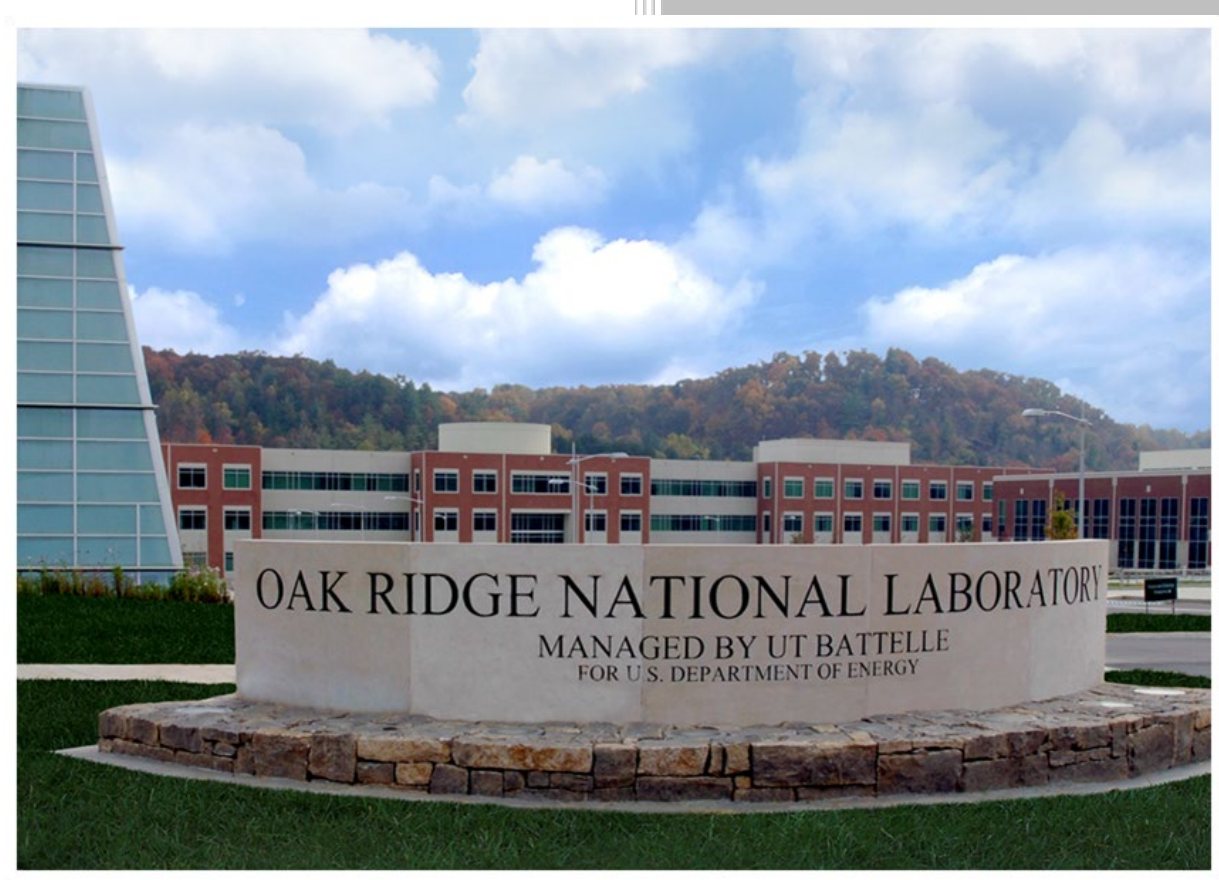

Approved for public release. Distribution is unlimited

M. Scott Greenwood Jake McMurray

September 2020 


\title{
DOCUMENT AVAILABILITY
}

Reports produced after January 1, 1996, are generally available free via US Department of Energy (DOE) SciTech Connect.

\section{Website www.osti.gov}

Reports produced before January 1, 1996, may be purchased by members of the public from the following source:

National Technical Information Service

5285 Port Royal Road

Springfield, VA 22161

Telephone 703-605-6000 (1-800-553-6847)

TDD 703-487-4639

Fax 703-605-6900

E-mail info@ntis.gov

Website http://classic.ntis.gov/

Reports are available to DOE employees, DOE contractors, Energy Technology Data Exchange representatives, and International Nuclear Information System representatives from the following source:

Office of Scientific and Technical Information

PO Box 62

Oak Ridge, TN 37831

Telephone 865-576-8401

Fax 865-576-5728

E-mail reports@osti.gov

Website http://www.osti.gov/contact.html

\begin{abstract}
This report was prepared as an account of work sponsored by an agency of the United States Government. Neither the United States Government nor any agency thereof, nor any of their employees, makes any warranty, express or implied, or assumes any legal liability or responsibility for the accuracy, completeness, or usefulness of any information, apparatus, product, or process disclosed, or represents that its use would not infringe privately owned rights. Reference herein to any specific commercial product, process, or service by trade name, trademark, manufacturer, or otherwise, does not necessarily constitute or imply its endorsement, recommendation, or favoring by the United States Government or any agency thereof. The views and opinions of authors expressed herein do not necessarily state or reflect those of the United States Government or any agency thereof.
\end{abstract}


Reactor \& Nuclear Systems Division

\section{Prototype Demonstration of the Integration of a Gibbs Energy Minimizer with TRANSFORM for Molten Salt Reactor Mass Accountancy Studies}

M. Scott Greenwood

Jake McMurray

September 2020

Prepared by

OAK RIDGE NATIONAL LABORATORY

Oak Ridge, TN 37831-6283

managed by

UT-BATTELLE, LLC

for the

US DEPARTMENT OF ENERGY

under contract DE-AC05-00OR22725 


\section{CONTENTS}

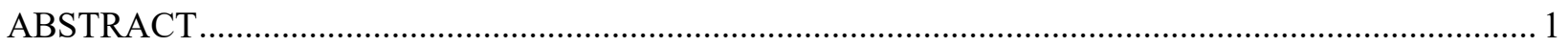

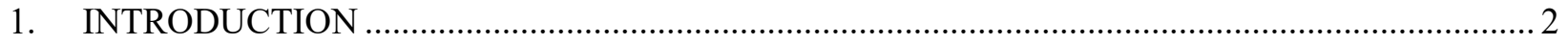

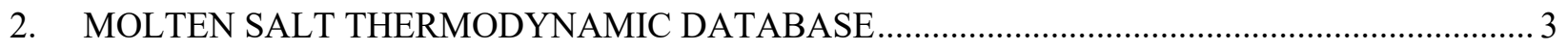

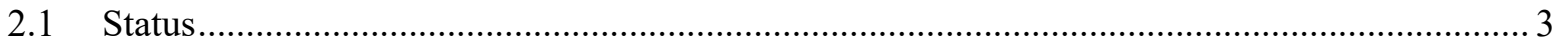

3. DYNAMIC MASS ACCOUNTANCY MODEL USING THE MSTDB ..................................... 5

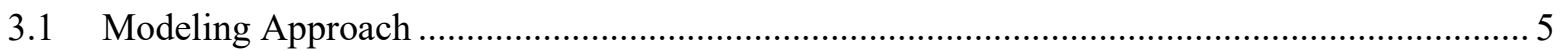

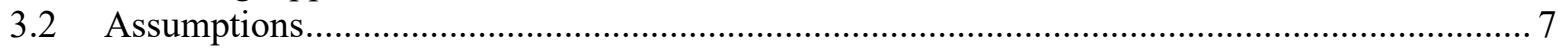

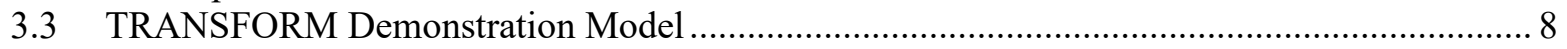

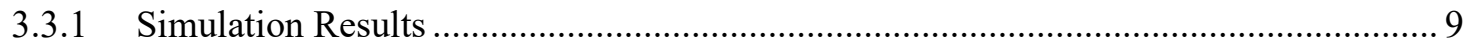

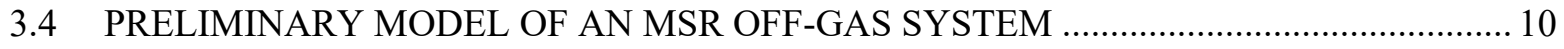

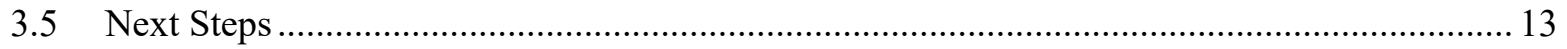

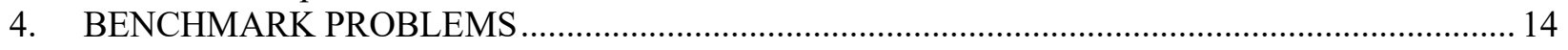

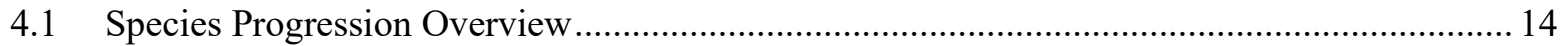

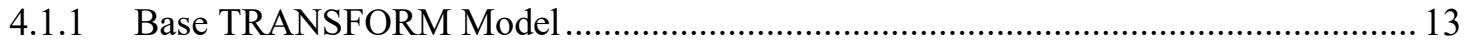

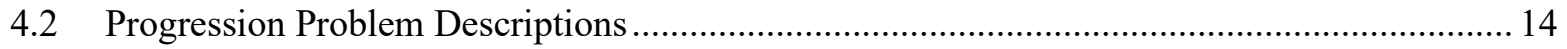

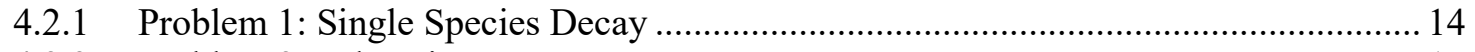

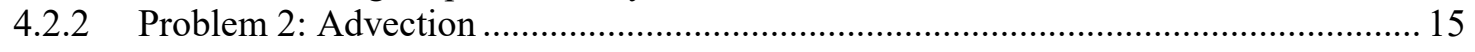

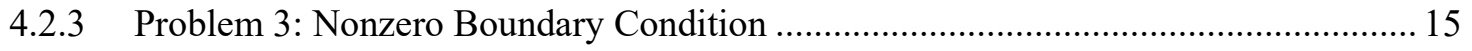

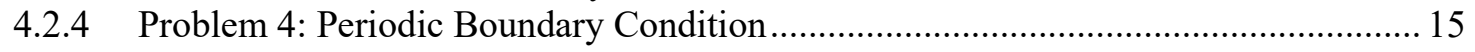

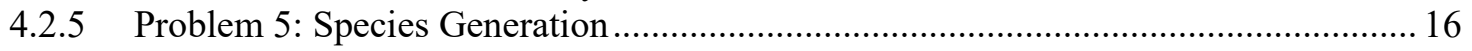

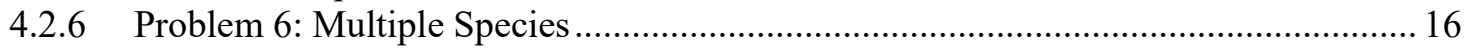

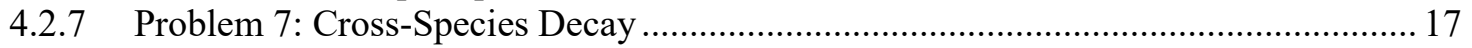

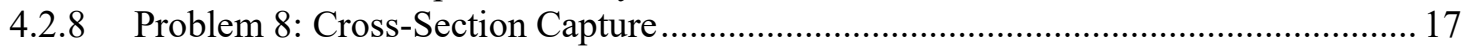

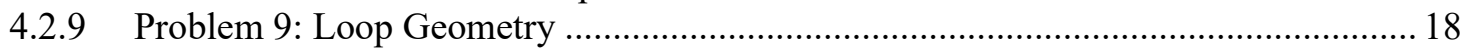

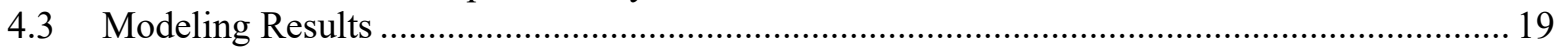

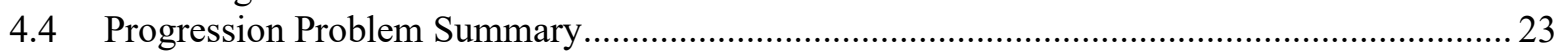

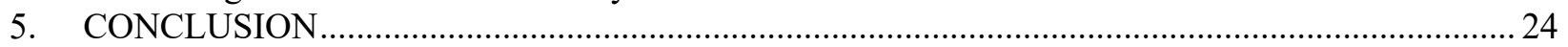

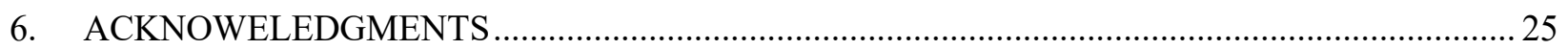

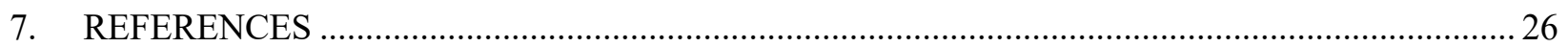




\section{LIST OF TABLES}

Table 1. Systems identified as important to commercial MSR vendors.

Table 2. Temperature-dependent partial pressures of Li-NaF-KF-Cs (41.85-10.35-37.8-10\% mole fraction)......

Table 3. Simulation summary for the simple off-gas system demonstration.......................................... 12

Table 4. Outline of progression problems.

Table 5. Base parameters of the TRANSFORM model that do not vary across progression problems.

Table 6. Summary of the model parameters for progression problem 1

Table 7. Summary of the model parameters for progression problem 2

Table 8. Summary of the model parameters for progression problem 3

Table 9. Summary of the model parameters for progression problem 4 .

Table 10. Summary of the model parameters for progression problem 5 .

Table 11. Summary of the model parameters for progression problem 6 .

Table 12. Summary of the model parameters for progression problem 7 .

Table 13. Summary of the model parameters for progression problem 8

Table 14. Summary of the model parameters for progression problem 9

Table 16. Summary of the difference between progression problems.

Table 15. Simulation summary for the progression problems 


\section{LIST OF FIGURES}

Figure 1. The integration of a simple component (i.e., gas-liquid interface) demonstration incorporated into reactor models, off-gas system models, and coupled dynamic system behavior analysis.

Figure 2. Illustration of the processes identified for transferring species from the salt phase to the gas phase.

Figure 3. Salt-to-gas interface transfer model demonstration of a simple static MSTDB integration.

Figure 4. Results from the demonstration model simulation: (a) salt and gas temperature, (b) gas pressure, (c) partial pressures, and (d) concentration in the gas of a few selected species........... 10

Figure 5. High-level depiction of a notional off-gas system and reactor model...................................... 11

Figure 6. TRANSFORM model of a simplified reactor and a notional off-gas system. ......................... 11

Figure 7. Species concentrations at different locations in the reactor and off-gas system. See Figure 6 for legend location reference.

Figure 8. Species concentration as a function of position at various time intervals in the simulation.

Figure 9. Base model for the demonstration of the species transport progression problems.................... 13

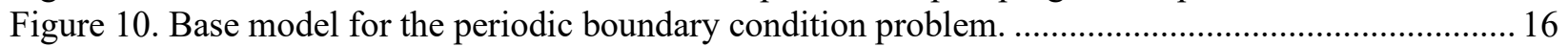

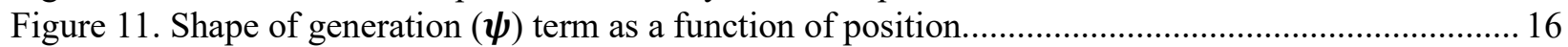

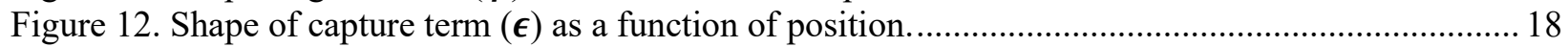

Figure 13. Base model for the periodic boundary condition with an additional loop element. .................. 18

Figure 14. Concentration of species $\boldsymbol{i}=\mathbf{1}$ as a function of position at discrete time steps for

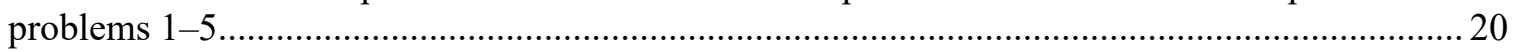

Figure 15. Concentration of species $\boldsymbol{i}=\mathbf{1}$ as a function of position at discrete time steps for

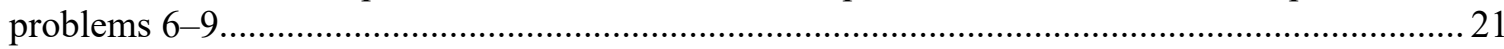

Figure 16. Concentration of species $\boldsymbol{i}=\mathbf{2}$ as a function of position at discrete time steps for

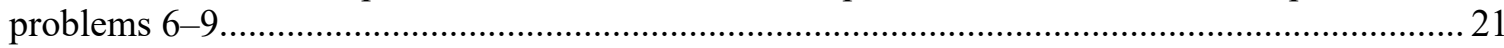

Figure 17. Concentration of species $\boldsymbol{i}=\mathbf{3}$ as a function of position at discrete time steps for

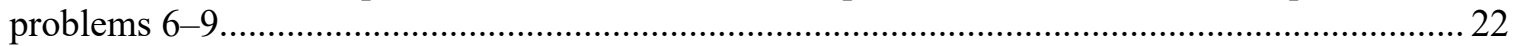

Figure 18. Concentration of species $\boldsymbol{i}=\mathbf{4}$ as a function of position at discrete time steps for problems 6-9. 


\section{ABBREVIATIONS}

AR

CALPHAD

DOE

GEM

LF

MSR

MSTDB

NE

TRANSFORM

$\mathrm{V} \& \mathrm{~V}$ advanced reactor

calculation of phase diagram

US Department of Energy

Gibbs energy minimizer

liquid-fueled

molten salt reactor

molten salt thermodynamic database

Office of Nuclear Energy

Transient Simulation Framework of Reconfigurable Models

validation and verification 


\begin{abstract}
Mass accountancy in a molten salt reactor (MSR) system is the ability to track and quantify the radioactive species throughout all portions of the reactor, not just the core. This is critical for the design, analysis, and regulation of these novel reactors. This report discusses a chemistry-based approach for understanding the chemical state, physical characteristics, and time-dependent location of a species throughout an MSR system. This report does not represent a completed capability; rather, it indicates that specific activities are needed (i.e., chemistry coupling and benchmark creation) and require sustained support to enable MSR development and deployment.
\end{abstract}




\section{INTRODUCTION}

Liquid-fueled (LF) molten salt reactors (MSRs) are a subset of MSRs in which the salt serves as both the coolant and fuel as the fissile material is dissolved in the salt. This fueled salt flows from the core, providing power to the reactor, and then travels to the primary heat exchanger and potentially to other auxiliary systems. This salt-fueled system provides unique challenges to modeling and simulation, as well as licensing and safeguards [1]. As part of an effort to provide methods for tracking, quantifying, and analyzing LF MSRs, this work discusses the chemistry capability that must be integrated into TRANSFORM (Transient Simulation Framework of Reconfigurable Models) [2] to provide more accurate salt composition analysis, especially for dynamic simulations.

Chemistry is a broad scientific discipline that includes the study and application of physics that range from atomistic- to macroscopic-length scales. For MSRs, modeling and simulation on the engineering scale will help design advanced reactors, inform their operation, and be critical for making a convincing licensing case for their deployment. Mass accountancy is the action of determining the chemical state, physical characteristics, and time-dependent location of a species in a system. It is directly related to understanding source terms and is an essential part of reactor performance predictions when coupled with thermal hydraulics, neutronics, and corrosion modeling.

This report briefly summarizes ongoing work associated with a thermodynamic database of molten salt reactors, which is critical for chemistry-based analysis. A prototype integration with the database is also discussed, as well as a high-level model of an off-gas system. The report then provides an initial set of progression problems that can be analyzed further in future publications to provide greater confidence in simulation results and an ability to quantify error via comparison with analytic and high-fidelity numerical approaches. 


\section{MOLTEN SALT THERMODYNAMIC DATABASE}

The US Department of Energy (DOE) Office of Nuclear Energy (NE) Advanced Reactor Technology Molten Salt Reactor campaign is generating thermochemical data for the continued development of the Molten Salt Thermodynamic Database (MSTDB) in coordination with the DOE-NE Nuclear Energy Advanced Modeling and Simulation program. The calculation of phase diagram (CALPHAD) approach [3] of thermodynamic assessments ${ }^{1}$ is being used to represent phase equilibria and the thermochemistry of chloride- and fluoride-based MSR salts with fission and activation products, additives, and other species (e.g., species that might be incorporated into a salt system due to corrosion reactions).

The MSTDB should be viewed as a collection of thermodynamic models that are developed from experiments or lower length scale computation that is available for coupling to other modeling and simulation codes for broad-based MSR performance predictions. The overarching aim of the program is to model important phenomena in MSRs with a physics-based approach to support the design, operation, and licensing of molten salt reactors.

\section{$2.1 \quad$ STATUS}

In FY 2019, DOE commissioned a report issued by Oak Ridge National Laboratory that describes the status of the MSTDB [4], which currently contains 21 elements with models for 55 molten salt binary solutions, 26 ternary molten salt solutions, five higher order liquid solutions (up to seven components), 14 solid solutions, and 140 multicomponent stoichiometric compounds.

Discussions with MSR developers have resulted in the drafting of a blueprint that identifies molten salt systems for which thermochemical and thermophysical properties must be known. These are described in Table 1. Thermochemical information exists for some systems. For example, FLiNaK and FLiBe are in MSTDB, but both could benefit from further experimental validation and parameter refinement.

\footnotetext{
${ }^{1}$ A thermodynamic assessment is a self-consistent set of Gibbs energy models for every phase in a system.
} 
Table 1. Systems identified as important to commercial MSR vendors.

\begin{tabular}{|c|c|}
\hline \multicolumn{2}{|c|}{ System } \\
\hline FLiNaK & $\mathrm{LiF}_{-\mathrm{BeF}-\mathrm{UF}_{3}}$ \\
\hline $\mathrm{LiF}_{-\mathrm{ThF}_{4}}$ & $\mathrm{NaCl}-\mathrm{MgCl} 2-\mathrm{PuCl}_{3}$ \\
\hline FLiNaK - I ${ }_{2}$ & $\mathrm{NaCl}-\mathrm{KCl}-\mathrm{PuCl}_{3}$ \\
\hline FLiNak - Cs & $\mathrm{NaCl}-\mathrm{KCl}-\mathrm{UCl}_{3}$ \\
\hline $\mathrm{UCl}_{3}-\mathrm{UCl}_{4}$ & $\mathrm{NaCl}-\mathrm{MgCl}_{2}-\mathrm{UCl}_{3}$ \\
\hline $\mathrm{NaCl}-\mathrm{MgCl}_{2}-\mathrm{ZrCl}_{4}$ & $\mathrm{LiF}-\mathrm{BeF}_{2}-\mathrm{iFP}^{\dagger}(\mathrm{FLiBe})$ \\
\hline $\mathrm{NaCl}-\mathrm{KCl}-\mathrm{ZrCl}_{4}$ & $\mathrm{LiF}-\mathrm{BeF}-\mathrm{PuF}_{3}$ \\
\hline $\mathrm{NaCl}-\mathrm{MgCl}_{2}-\mathrm{AlCl}_{3}$ & $\mathrm{NaCl}-\mathrm{MgCl}_{2}-\mathrm{SFPCl}_{\mathrm{x}}{ }^{*}$ \\
\hline $\mathrm{NaCl}-\mathrm{KCl}-\mathrm{AlCl}_{3}$ & $\mathrm{NaCl}-\mathrm{MgCl}_{2}-\mathrm{iFP}^{\dagger}$ \\
\hline $\mathrm{NaCl}-\mathrm{ThCl}_{4}-6$ mole$\% \mathrm{PuCl}_{3}$ & $\mathrm{NaCl}-\mathrm{KCl}-\mathrm{sFPCl}_{\mathrm{x}}{ }^{*}$ \\
\hline $\mathrm{UF}_{4}-\mathrm{UF}_{3}$ & $\mathrm{NaCl}-\mathrm{KCl}-\mathrm{iFP}^{\dagger}$ \\
\hline $\mathrm{LiF}_{-\mathrm{BeF}-\mathrm{UF}_{4}}$ & LiF-BeF-sFPF $_{x}{ }^{*}$ \\
\hline $\mathrm{LiF}_{-\mathrm{BeF}-\mathrm{ThF}_{4}}$ & \\
\hline
\end{tabular}




\section{DYNAMIC MASS ACCOUNTANCY MODEL USING THE MSTDB}

This section describes the model created to demonstrate the method with which the MSTDB will be coupled via a dynamic system model, which was created by using TRANSFORM. As the ability to couple these tools progresses, the simplified case of a component, such as an MSR headspace, can be incorporated into a full-system model, including auxiliary systems, such as off-gas treatment (Figure 1). The initial demonstration explored in this work is a critical first step toward this integration since it solidifies the first specific tasks needed to achieve the expected result — a truly physics-based mass accountancy tool capable of steady-state and dynamic investigations.

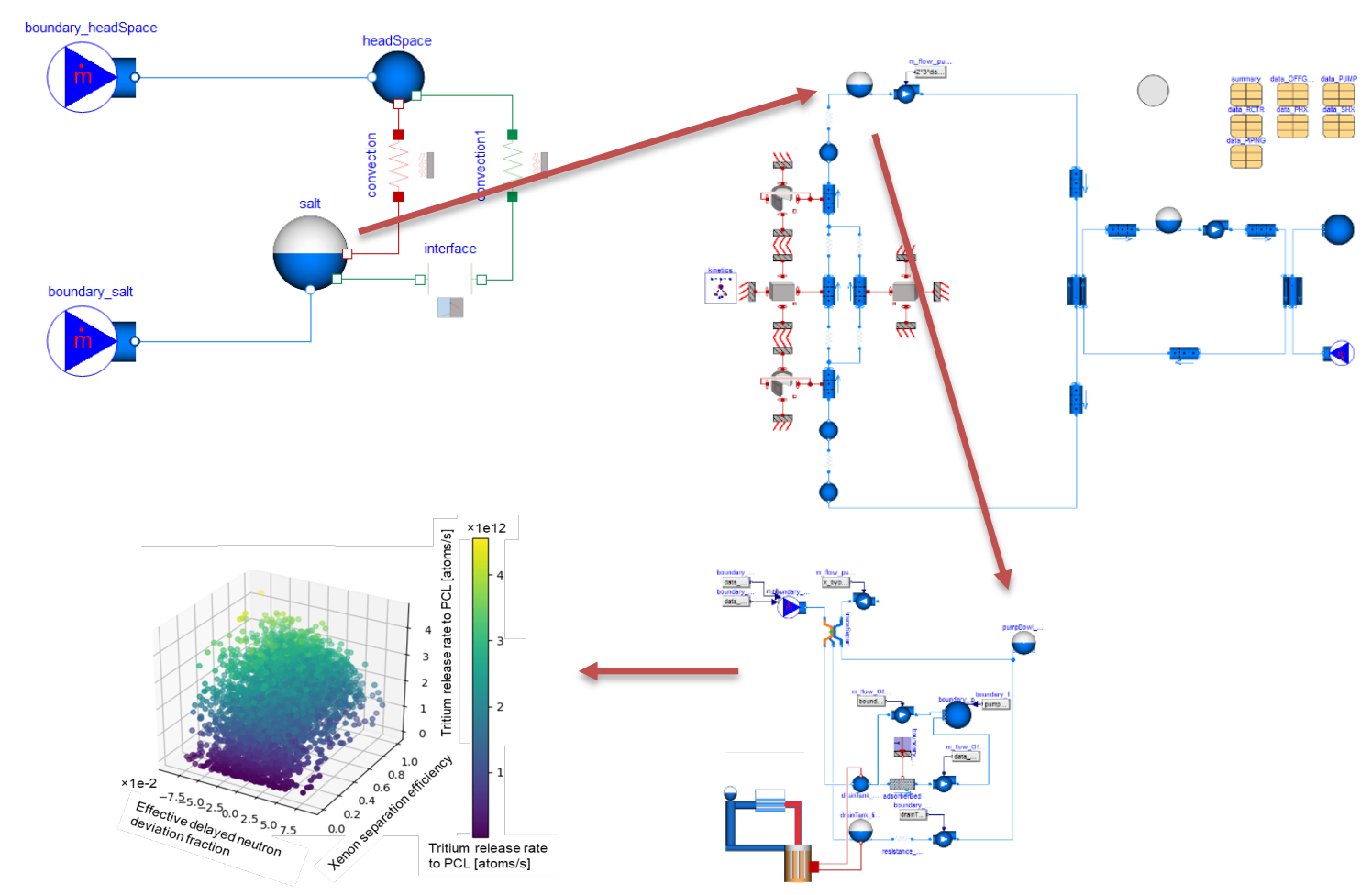

Figure 1. The integration of a simple component (i.e., gas-liquid interface) demonstration incorporated into reactor models, off-gas system models, and coupled dynamic system behavior analysis.

\subsection{MODELING APPROACH}

Thermodynamics is fundamental to mass accountancy. It provides the chemical state of species in the system. For modeling phase transformations and mass transport, the dominant driving force is the chemical potential, $\mu$, of a species. As stated in Olander [5], for treating diffusion, assuming a binary mixture of species $A$ and $B$ for simplicity, the mass flux of species $A, J_{A}$, is:

$$
J_{A}=-L_{11}\left(\nabla \mu_{A}\right)_{T}-L_{12} \frac{\nabla T}{T}
$$

where $T$ is temperature that $L_{11}$ is related to the diffusion coefficient. The term $L_{12}$ is a coefficient resulting from the Dufour and Soret effect, which is heat transfer due to a $\nabla \mu$ for the former and mass transport from 
a $\nabla T$ for the latter. By neglecting the Soret effect (i.e., temperature gradient driven or thermal diffusion) and assuming an ideal mixture, which is generally valid for gasses at low pressures at normal to high temperatures, and $1 \mathrm{D}$, it can be shown that:

$$
J_{A}=D \nabla C_{A}=D \frac{d C_{A}}{d x},
$$

where $C_{A}$ is the concentration of species $A$. This formulation is analogous to Fick's law for heat transfer, and because $D$ acts in the same way as a heat transfer coefficient (i.e., heat and mass transfer analogy), it is a constant of proportionality defined by the specific case under scrutiny [6]. Therefore, the relation to define the movement of a dilute, noninteracting species can be defined by Eq. (3) ( $k$ is the mass transfer coefficient and $A$ is interfacial area) and is the driving function used in the modeling approach for transfer from the interface to the gas phase:

$$
\frac{d\left(m_{i}\right)}{d t}=k A\left(C_{g a s, \text { interface, } i}-C_{g a s, b u l k, i}\right) .
$$

A coupling demonstration of TRANSFORM with the MSTDB was performed to understand the gaps in modeling capability for developing an effective and sophisticated mass accountancy modeling tool. The demonstration selected was a salt-gas interface such as would be expected in the headspace of an MSR and the off-gas system, if applicable. Figure 2 illustrates the concept in which species in a bulk salt $\left(C_{s a l t, b u l k, i}\right)$ transfer over time $\left(d\left(m_{i}\right) / d t\right)$ from the salt to the gas phase $\left(C_{g a s, b u l k, i}\right)$. In the figure, $R$ is the resistance to mass transfer at the respective locations. Physics-based modeling and simulating mass transport requires thermodynamic inputs (i.e., phase equilibria and chemical potentials) that drive diffusion. To interpret the data in the MSTDB for calculations, a Gibbs energy minimizer (GEM) is required. The goal is an integrated GEM with TRANSFORM. However, for demonstration purposes, an external GEM called FactSage [7] was used. 


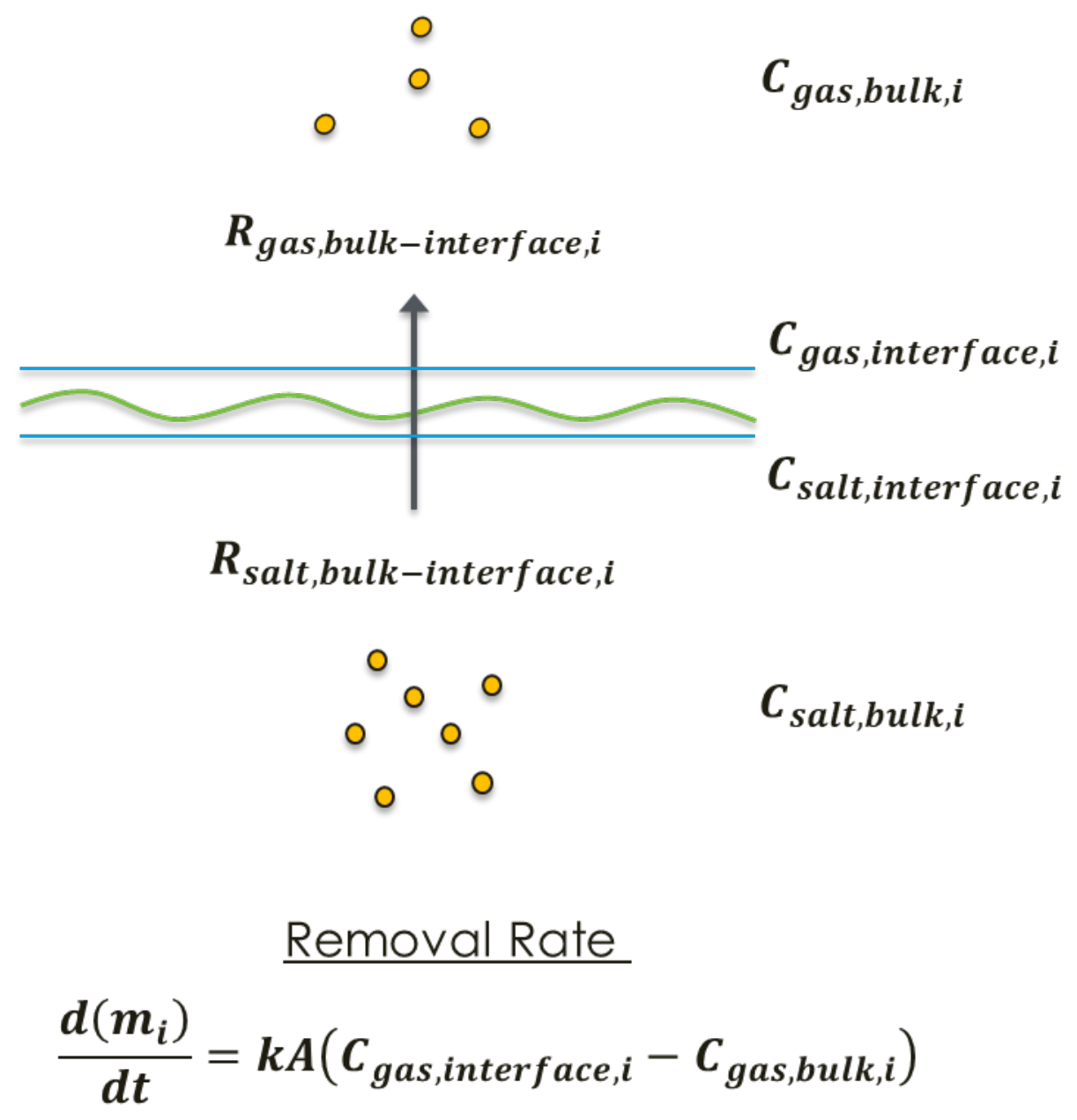

Figure 2. Illustration of the processes identified for transferring species from the salt phase to the gas phase.

\subsection{ASSUMPTIONS}

Because FactSage is a commercial, proprietary software, direct coupling to TRANSFORM or any other multiphysics code is impossible. Therefore, to demonstrate the capability, some simplifying assumptions are made. The molten salt is considered to maintain a constant composition. This, along with the local temperature, sets the chemical potential of each salt constituent. For this work, mass transport is driven by differences in concentrations in the vapor phase. Future work will include implanting chemical potentialdriven mass transport. The complete list of assumptions includes the following.

1. The salt makeup is $41.85-10.35-37.8-10 \%$ by mole fraction for Li-NaF-KF-Cs at time $=0$.

2. The gas phase bulk concentration $\left(C_{\text {gas,bulk,i }}\right)$ (i.e., partial pressure of salt species) is equal to 0 at time $=0$.

3. There is no salt ingress/egress or sweep gas ingress/ egress.

4. The mass transfer to the liquid interface from the bulk salt is very rapid compared with mass transfer from the gas interface into the gas bulk $\left(R_{\text {salt,bulk-interface, } i} \ll R_{\text {gas,bulk-interface, } i}\right)$ (i.e., $C_{\text {salt }, b u l k, i}$ is equal to the liquid interface concentration, $C_{\text {salt,interface, } i}$ ).

5. Mass transfer from liquid to gas at the interface is very fast compared with other mass transfer dynamics. Therefore, the gas interphase concentration can be directly derived from the liquid interphase concentration computed by using the FactSage GEM. 
6. Other parameters that are highly problem-specific (e.g., surface area and mass transfer coefficient) were arbitrarily selected in the example. These values are easily updated for specific studies and do not impact the main motivation for this demonstration, which is to explore how to couple the MSTDB to TRANSFORM.

An open-source GEM directly coupled to TRANSFORM allows many of these assumptions to be removed, resulting in a more realistic modeling result. Other assumption can readily be relaxed in TRANSFORM, as necessary, with the addition of other components.

\subsection{TRANSFORM DEMONSTRATION MODEL}

Figure 3 shows the TRANSFORM model used in this demonstration. The MSTDB was coupled to TRANSFORM in a static fashion by obtaining temperature-dependent partial pressures (Table 2) for the salt species (partialPressures). These partial pressures were then converted to molar concentrations by using the ideal gas law and were used to set the gas-side interface concentration. Mass transfer from the interface to the bulk gas-phase was then determined by using a mass transfer coefficient (green line). Heat transfer (red line) was incorporated by setting a boundary temperature that represented the bulk salt temperature and then determining the rate of heat transfer with the temperature difference between the gas and salt by using a specified heat transfer coefficient. As stated in the assumptions, the mass flow boundary was set to zero-flow (i.e., to sweep gas), and the salt composition was assumed to be fixed-no change in partial pressures except as a function of temperature - no matter how much mass transfer occurred. Other parameters (e.g., surface areas, mass transfer coefficients) were not specified because they are entirely arbitrary for this demonstration.
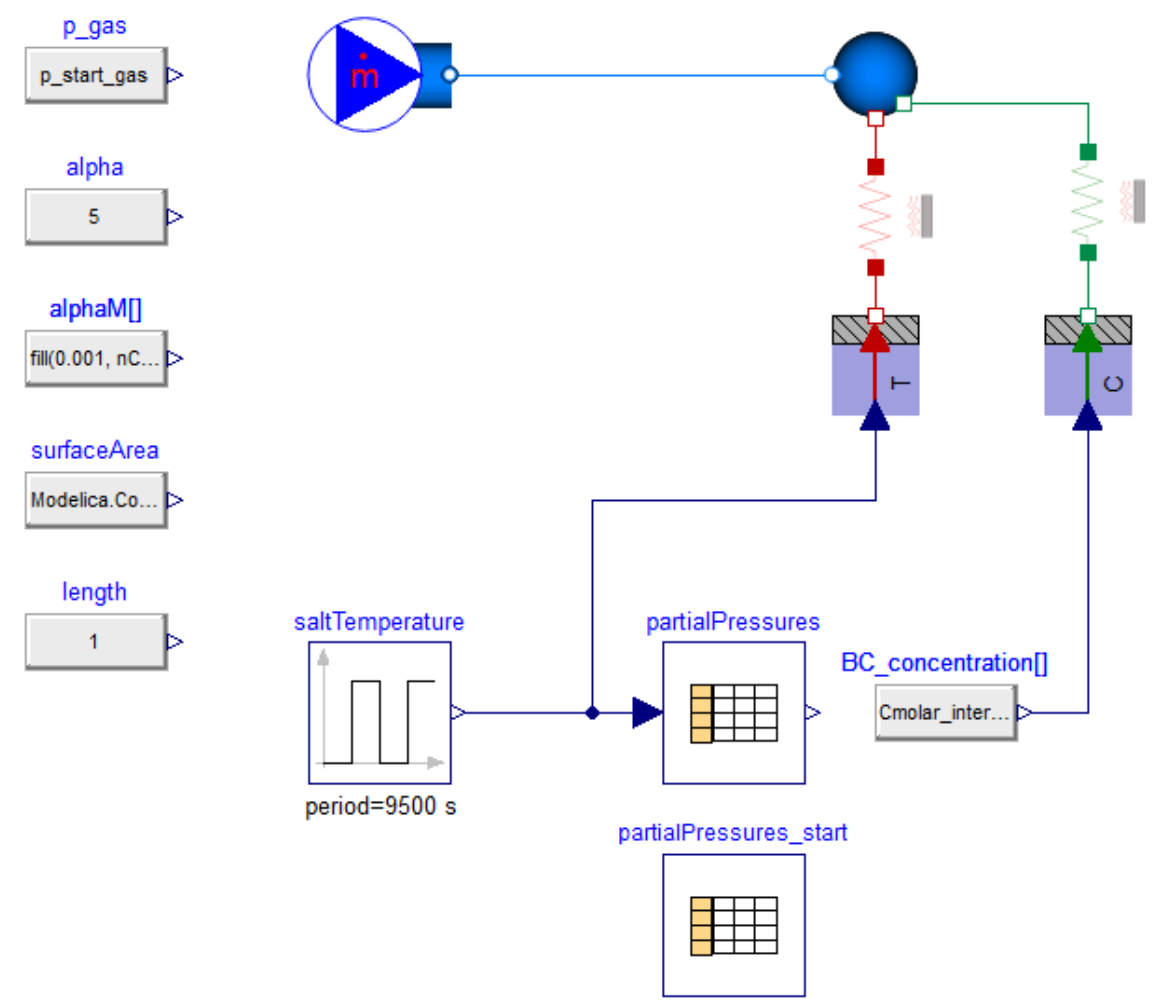

Figure 3. Salt-to-gas interface transfer model demonstration of a simple static MSTDB integration. 
Table 2. Temperature-dependent partial pressures of Li-NaF-KF-Cs (41.85-10.35-37.8-10\% mole fraction).

\begin{tabular}{|c|c|c|c|c|c|c|c|c|c|c|}
\hline $\mathbf{T}\left({ }^{\circ} \mathbf{C}\right)$ & $\mathbf{L i}$ & LiF & $\mathrm{Na}$ & $\mathrm{NaF}$ & $\mathrm{F}_{2} \mathrm{Na}_{2}$ & $\mathrm{~F}_{3} \mathrm{Na}_{3}$ & K & KF & $\mathbf{K}_{2} \mathbf{F}_{2}$ & Cs \\
\hline 0 & $6.0 \mathrm{E}-35$ & $5 \mathrm{E}-45$ & $2.4 \mathrm{E}-17$ & $9.0 \mathrm{E}-47$ & $9.3 \mathrm{E}-50$ & $2.3 \mathrm{E}-62$ & $9.3 \mathrm{E}-13$ & $1.3 \mathrm{E}-38$ & $1.9 \mathrm{E}-43$ & $1.2 \mathrm{E}-10$ \\
\hline 50 & $3 \mathrm{E}-29$ & $5 \mathrm{E}-37$ & $6.3 \mathrm{E}-14$ & $2.6 \mathrm{E}-38$ & $1 \mathrm{E}-40$ & 4.6E-51 & $4.0 \mathrm{E}-10$ & $9 \mathrm{E}-31$ & $2.5 \mathrm{E}-35$ & $2.2 \mathrm{E}-08$ \\
\hline 100 & $2.6 \mathrm{E}-24$ & $8.9 \mathrm{E}-31$ & $1.9 \mathrm{E}-11$ & $4.1 \mathrm{E}-32$ & $4.7 \mathrm{E}-34$ & $8.1 \mathrm{E}-43$ & $3.3 \mathrm{E}-08$ & $3.1 \mathrm{E}-26$ & $2.1 \mathrm{E}-29$ & $9.9 \mathrm{E}-07$ \\
\hline 150 & $6.7 \mathrm{E}-21$ & $3.2 \mathrm{E}-26$ & $1.5 \mathrm{E}-09$ & $2.1 \mathrm{E}-27$ & $5.1 \mathrm{E}-29$ & $1.5 \mathrm{E}-36$ & $9.2 \mathrm{E}-07$ & $2.9 \mathrm{E}-22$ & $6.6 \mathrm{E}-25$ & $1.7 \mathrm{E}-05$ \\
\hline 200 & 18 & 1.2 & $4.4 \mathrm{I}$ & & & & & $9 \mathrm{E}-19$ & & $1.6 \mathrm{E}-04$ \\
\hline 250 & $4.9 \mathrm{E}-16$ & $9.4 \mathrm{E}-20$ & $6.8 \mathrm{E}-07$ & -20 & $6.9 \mathrm{H}$ & & -04 & -16 & & $9.6 \mathrm{E}-04$ \\
\hline 300 & & $2.3 \mathrm{E}-17$ & $6.4 \mathrm{E}-06$ & & & & $5.6 \mathrm{E}-04$ & $1.5 \mathrm{E}-14$ & & $4.2 \mathrm{E}-03$ \\
\hline 350 & E-13 & $2.2 \mathrm{E}-15$ & $4.2 \mathrm{E}-05$ & & & & $2.4 \mathrm{E}-03$ & & E-14 & $1.4 \mathrm{E}-02$ \\
\hline 400 & & $1.1 \mathrm{E}-13$ & & & & & & & & $4.0 \mathrm{E}-02$ \\
\hline 450 & & $3.1 \mathrm{E}-12$ & $9.5 \mathrm{E}-04$ & & & & & & & E-02 \\
\hline 465 & & $7.6 \mathrm{E}-12$ & $1.6 \mathrm{E}-03$ & & & & & & & $1.2 \mathrm{E}-01$ \\
\hline 481 & & & & & & & & & & \\
\hline 500 & $2.8 \mathrm{E}-09$ & $4.8 \mathrm{E}-11$ & $3.8 \mathrm{E}-03$ & $1.0 \mathrm{E}-11$ & $2.1 \mathrm{E}-12$ & $7.9 \mathrm{E}-16$ & $5.5 \mathrm{E}-02$ & 3.4E-09 & $2.4 \mathrm{E}-10$ & 2.1E-01 \\
\hline 550 & $1.9 \mathrm{E}-08$ & $5.0 \mathrm{E}-10$ & $9.6 \mathrm{E}-03$ & $1.1 \mathrm{E}-10$ & $1.9 \mathrm{E}-11$ & $1.0 \mathrm{E}-14$ & $1.2 \mathrm{E}-01$ & $2.5 \mathrm{E}-08$ & $1.9 \mathrm{E}-09$ & $4.0 \mathrm{E}-01$ \\
\hline 572 & $4.1 \mathrm{E}-08$ & $1.3 \mathrm{E}-09$ & $1.4 \mathrm{E}-02$ & $2.7 \mathrm{E}-10$ & 4.4E-11 & $2.9 \mathrm{E}-14$ & $1.7 \mathrm{E}-01$ & $5.7 \mathrm{E}-08$ & 4.4E-09 & $5.2 \mathrm{E}-01$ \\
\hline 600 & $1.0 \mathrm{E}-07$ & 3.9E-09 & $2.2 \mathrm{E}-02$ & $8.1 \mathrm{E}-10$ & $1.2 \mathrm{E}-10$ & $9.6 \mathrm{E}-14$ & 2.4E-01 & $1.5 \mathrm{E}-07$ & $1.2 \mathrm{E}-08$ & $6.9 \mathrm{E}-01$ \\
\hline 605 & $1.2 \mathrm{E}-07$ & 4.7E-09 & $2.3 \mathrm{E}-02$ & $9.7 \mathrm{E}-10$ & $1.4 \mathrm{E}-10$ & $1.2 \mathrm{E}-13$ & 2.6E-01 & $1.7 \mathrm{E}-07$ & $1.4 \mathrm{E}-08$ & 7.2E-01 \\
\hline 650 & $4.0 \mathrm{E}-07$ & $2.5 \mathrm{E}-08$ & $3.5 \mathrm{E}-02$ & 4.6E-09 & $5.6 \mathrm{E}-10$ & $5.4 \mathrm{E}-13$ & $4.5 \mathrm{E}-01$ & $8.5 \mathrm{E}-07$ & $8.4 \mathrm{E}-08$ & $5.1 \mathrm{E}-01$ \\
\hline 658 & & & & & & & & & & 4.7E-01 \\
\hline 700 & $9.9 \mathrm{E}-07$ & $1.3 \mathrm{E}-07$ & $4.2 \mathrm{E}-02$ & $2.3 \mathrm{E}-08$ & $2.3 \mathrm{E}-09$ & $2.8 \mathrm{E}-12$ & $5.1 \mathrm{E}-01$ & $3.5 \mathrm{E}-06$ & $3.7 \mathrm{E}-07$ & $4.5 \mathrm{E}-01$ \\
\hline 750 & $2.1 \mathrm{E}-06$ & $5.6 \mathrm{E}-07$ & $4.7 \mathrm{E}-02$ & $9.5 \mathrm{E}-08$ & $8.5 \mathrm{E}-09$ & $1.3 \mathrm{E}-11$ & $5.3 \mathrm{E}-01$ & $1.2 \mathrm{E}-05$ & $1.3 \mathrm{E}-06$ & $4.3 \mathrm{E}-01$ \\
\hline 800 & $4.2 \mathrm{E}-06$ & $2.1 \mathrm{E}-06$ & $5.2 \mathrm{E}-02$ & $3.5 \mathrm{E}-07$ & $2.7 \mathrm{E}-08$ & $5.1 \mathrm{E}-11$ & $5.4 \mathrm{E}-01$ & $3.8 \mathrm{E}-05$ & $4.1 \mathrm{E}-06$ & $4.1 \mathrm{E}-01$ \\
\hline 850 & $8.0 \mathrm{E}-06$ & $6.9 \mathrm{E}-06$ & $5.7 \mathrm{E}-02$ & $1.1 \mathrm{E}-06$ & & $1.7 \mathrm{E}-10$ & $5.6 \mathrm{E}-01$ & $1.0 \mathrm{E}-04$ & $1.1 \mathrm{E}-05$ & $3.9 \mathrm{E}-01$ \\
\hline 900 & $1.4 \mathrm{E}-05$ & $2.1 \mathrm{E}-05$ & $6.2 \mathrm{E}-02$ & $3.3 \mathrm{E}-06$ & $2.0 \mathrm{E}-07$ & $5.0 \mathrm{E}-10$ & $5.7 \mathrm{E}-01$ & $2.6 \mathrm{E}-04$ & $2.8 \mathrm{E}-05$ & $3.7 \mathrm{E}-01$ \\
\hline 950 & $2.4 \mathrm{E}-05$ & $5.5 \mathrm{E}-05$ & $6.7 \mathrm{E}-02$ & $8.6 \mathrm{E}-06$ & $4.6 \mathrm{E}-07$ & $1.3 \mathrm{E}-09$ & $5.8 \mathrm{E}-01$ & $6.1 \mathrm{E}-04$ & $6.5 \mathrm{E}-05$ & $3.5 \mathrm{E}-01$ \\
\hline 1,000 & $3.9 \mathrm{E}-05$ & $1.4 \mathrm{E}-04$ & 7.2E-02 & $2.1 \mathrm{E}-05$ & $1.0 \mathrm{E}-06$ & $3.2 \mathrm{E}-09$ & $5.9 \mathrm{E}-01$ & $1.3 \mathrm{E}-03$ & $1.4 \mathrm{E}-04$ & $3.4 \mathrm{E}-01$ \\
\hline
\end{tabular}

Pressures are in Pa.

Off-pattern temperature increments are associated with phase transitions.

\subsubsection{Simulation Results}

The model shown in Figure 3 was simulated for 10,000 seconds, and a step temperature change of $100^{\circ} \mathrm{C}$ in the salt temperature was imposed to exercise the temperature dependence of the partial pressures. Figure 4 presents a few select parameters that demonstrate: (a) the increase in the gas/headspace temperature over time, (b) the resulting pressure increase, (c) the change in partial pressures at the interface due to the temperature change, and (d) the resulting increased rate in a buildup of species - inflection in curvefollowed by the decrease as species flow back into the salt. 

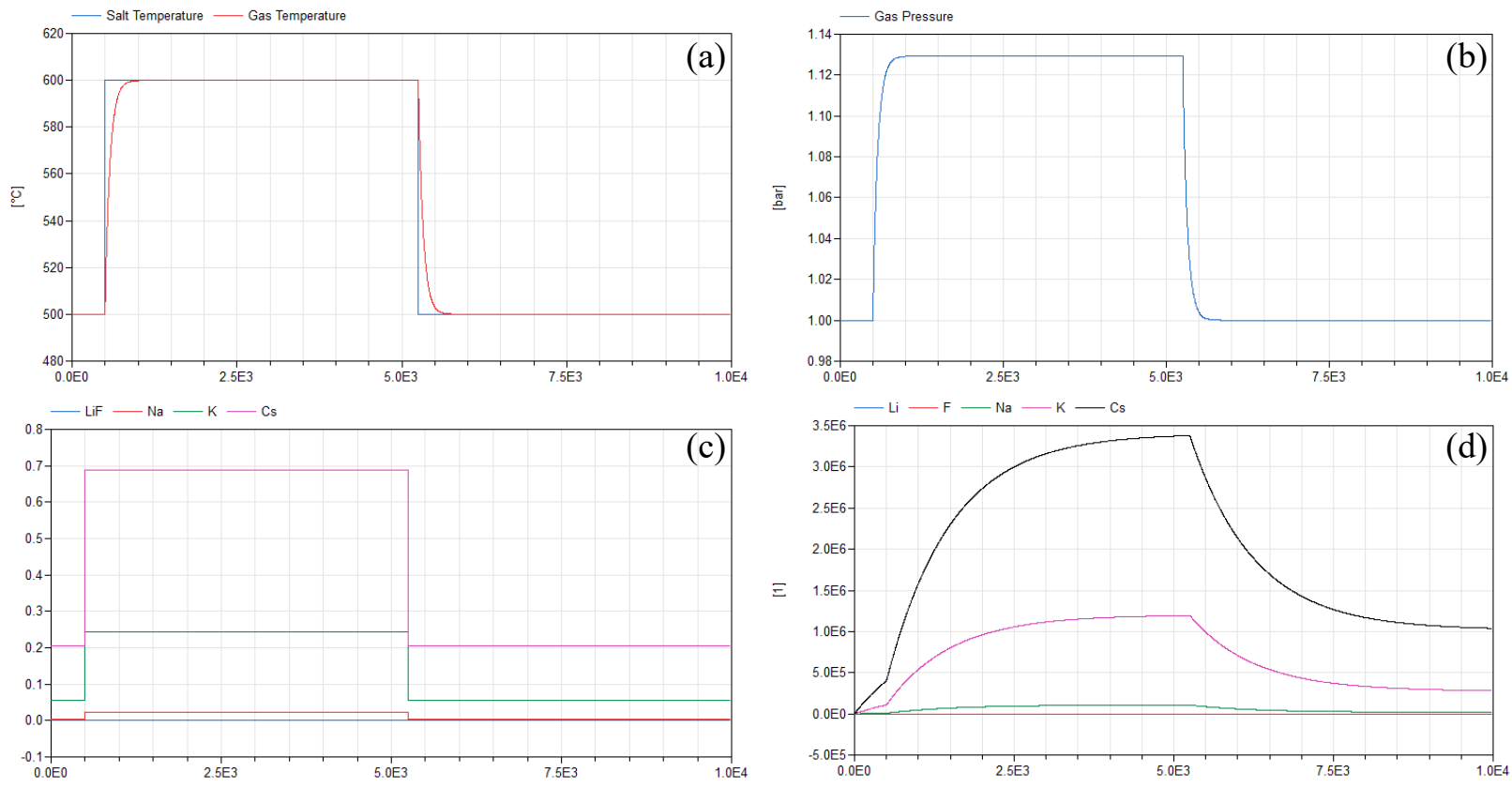

Figure 4. Results from the demonstration model simulation: (a) salt and gas temperature, (b) gas pressure, (c) partial pressures, and (d) concentration in the gas of a few selected species.

\subsection{PRELIMINARY MODEL OF AN MSR OFF-GAS SYSTEM}

One principal application of integrating MSTDB into a system code such as TRANSFORM is to be able to create a dynamic model of an MSR with an off-gas system. This model type can then be applied to many studies, such as designing and testing experimental facilities and safeguards studies. While the coupling with a GEM is developed, interim models can be generated to move forward, understanding other aspects of coupling an off-gas and reactor model. A high-level off-gas system was created by modeling the decay of a meta-stable xenon isotope to Cs (Figure 5). This system was modeled in TRANSFORM, as shown Figure 6. The geometric details of the reactor and source term generation are taken from Section 4. The simulation settings and high-level simulations statistics for this simulation are provided in Table 3. 


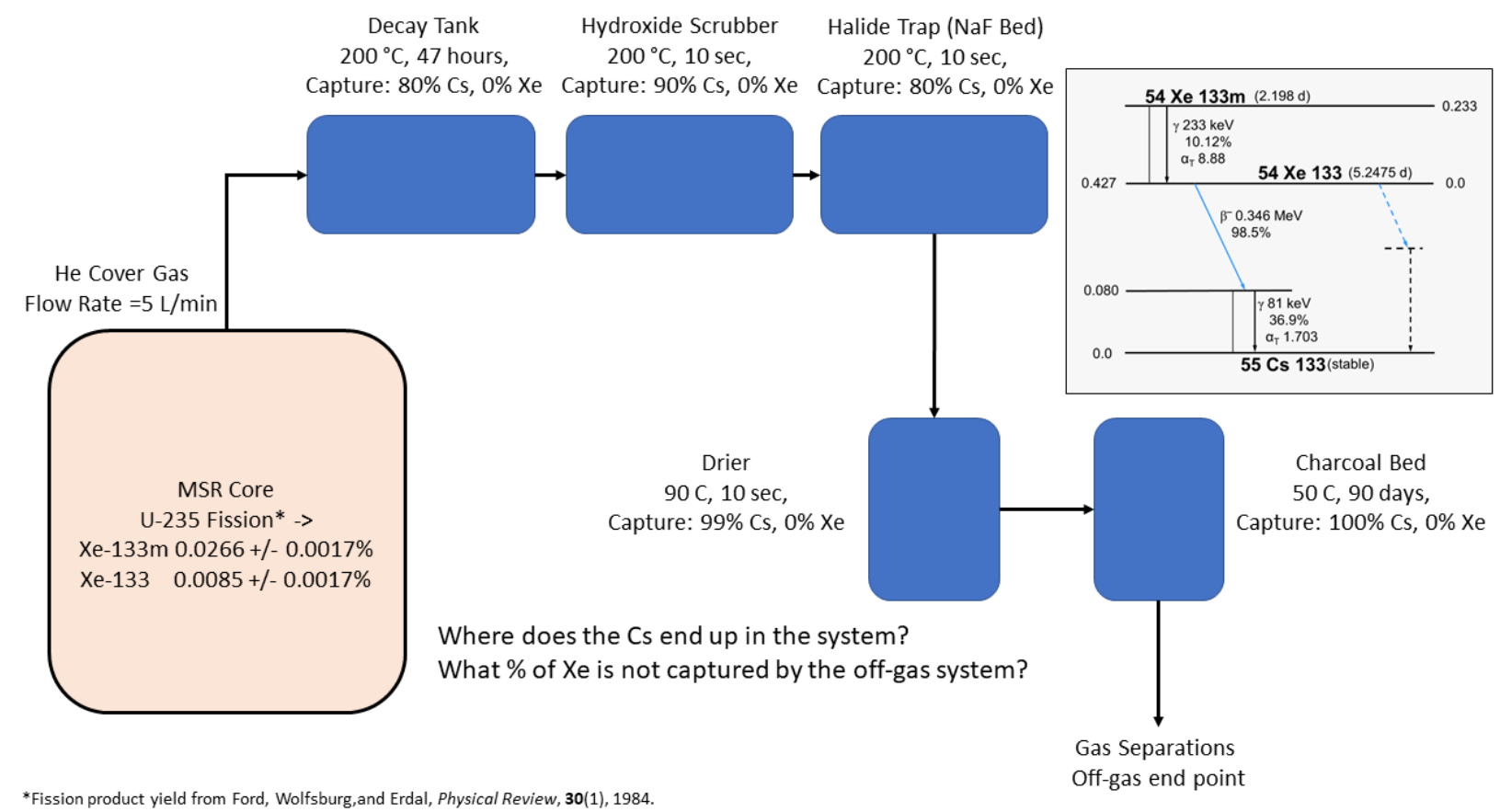

Figure 5. High-level depiction of a notional off-gas system and reactor model.

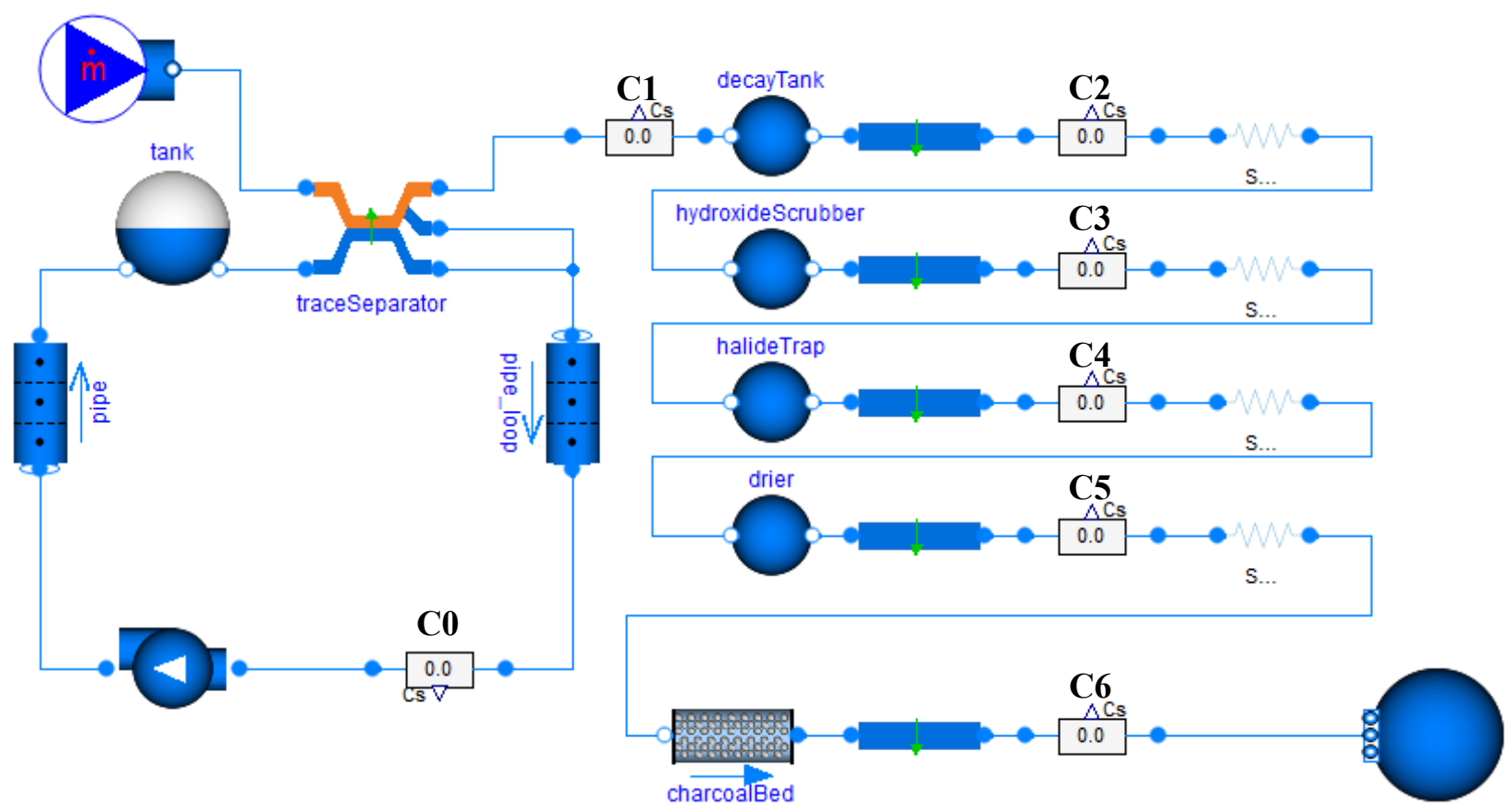

Figure 6. TRANSFORM model of a simplified reactor and a notional off-gas system. 
Table 3. Simulation summary for the simple off-gas system demonstration.

\begin{tabular}{lc}
\hline Parameter & Value \\
\hline Simulation time (d) & 200 \\
\hline Real time (s) & 1.129 \\
\hline Solver & Esdirk45a \\
\hline Solution tolerance & $1.0 \mathrm{e}-6$ \\
\hline Equations & 6,635 \\
\hline
\end{tabular}

The results of a 200-day simulation are shown in Figure 7 and Figure 8 in which the off-gas system started as completely clean (i.e., devoid of any species). Figure 7 illustrates that the peak in each species is dependent on the hold-up time throughout the system and the half-life of the various species. Figure 8 shows the propagation of the wave of species as the various forms of Xe decay and Cs build up over time, reaching a steady state condition by around day 200. The scales are removed in these figures because these preliminary results are only for showing trajectories. Future work will focus on maturing specific components of the off-gas system to be more physics-based (e.g., hydroxide scrubber) and other improvements for quantitative analysis, such as MSTDB integration, as available.

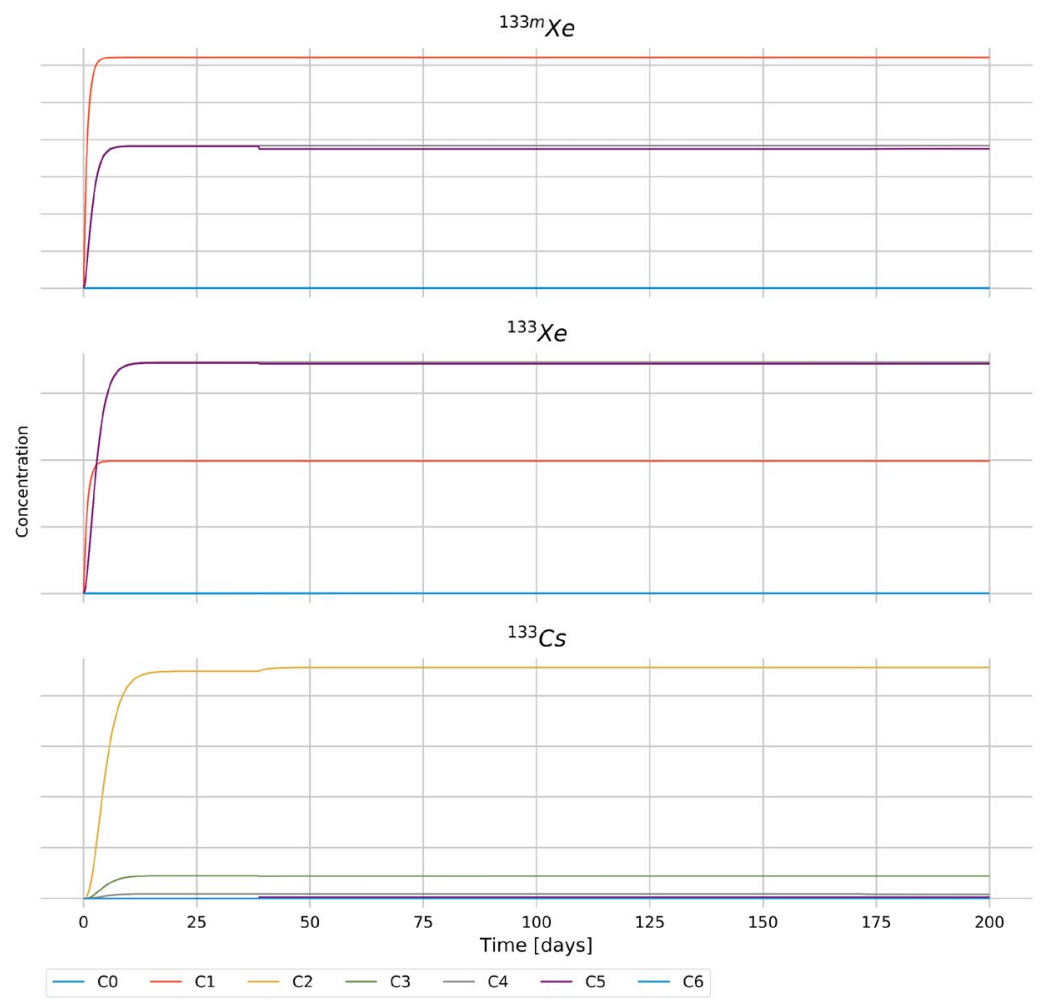

Figure 7. Species concentrations at different locations in the reactor and off-gas system. See Figure 6 for legend location reference. 


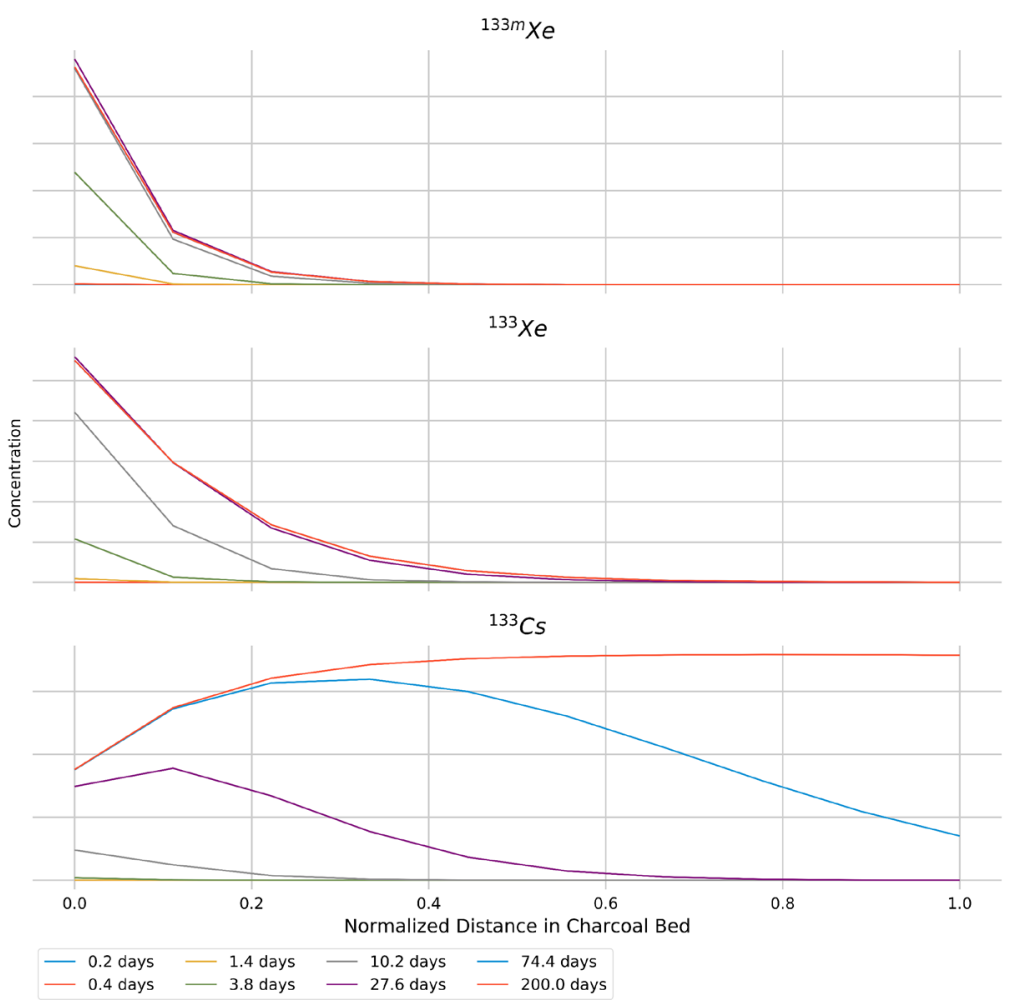

Figure 8. Species concentration as a function of position at various time intervals in the simulation.

\subsection{NEXT STEPS}

Although the presented simulations provide time-dependent results, the assumptions stated previously mean that these results are not truly accurate for a dynamic simulation. If there are "appreciable" amounts of species leaving the salt, then the original composition of the salt will change, alter the partial pressures at the interface, and thereby change the transport to the gas phase. An additional limitation is that an operating reactor will have a salt composition that changes with time based on its operational modes. This composition change, especially for more rapid transients, is another item that will impact the salt composition and species transport result. Therefore, one clear outcome of this work is the exploration and development of an integrated GEM capability with TRANSFORM. This will be an area of future work to develop and deliver detailed, dynamic mass accountancy simulations. However, for studies that do not require the same level of speciation fidelity desired from a MSTDB/GEM-type approach, the existing capabilities within TRANSFORM for mass accountancy might be appropriate because they are highly customizable to the case of interest.

Benchmark problems for validation and verification $(V \& V)$ of the results of mass accountancy models and MSTDB couplings must also be developed to ensure that the obtained results are correct and their accuracy is understood. Ongoing efforts to develop benchmark problems might help V\&V models, such as the one presented. The next section presents some preliminary models of a potential benchmark. MSTDB- and GEM-related work will require their own benchmark problems to be developed in concert with the coupling activity to ensure that coupling is performing as expected. 


\section{BENCHMARK PROBLEMS}

\subsection{SPECIES PROGRESSION OVERVIEW}

A series of species transport progression problems that range from nearly trivial to complicated and realistic are currently under development to help tool developers check and improve their ability to model the movement of radioisotopes within their modeling approach and demonstrate the soundness of methods to users. The development of those problems [8] is ongoing under another DOE NE program. However, a potential portion of the progression problems (Table 4) have been sufficiently developed that a TRANSFORM model can be produced for preliminary comparisons. The problem and model are briefly summarized with a more detailed presentation of boundary conditions, analytical solutions, and so on left to the progression problem publication. Quantitative comparisons of the TRANSFORM model performance for the formal progression problem solution are not presented because they will be assessed once the progression problem publication is complete. 
Table 4. Outline of progression problems.

\begin{tabular}{|c|c|c|c|c|c|c|c|c|c|}
\hline Problem & 1 & 2 & 3 & 4 & 5 & 6 & 7 & 8 & 9 \\
\hline Geometry & Core & Core & Core & Core & Core & Core & Core & Core & Core and loop \\
\hline Boundary & $\mathrm{N} / \mathrm{A}$ & $\begin{array}{l}\text { Constant, } \\
\text { zero }\end{array}$ & $\begin{array}{l}\text { Constant, } \\
\text { nonzero }\end{array}$ & Periodic & Periodic & Periodic & Periodic & Periodic & Periodic \\
\hline \multirow{6}{*}{ 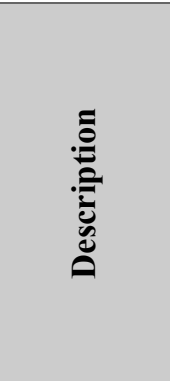 } & Decay & Decay & Decay & Decay & Decay & Decay & Decay & Decay & Decay \\
\hline & & Advection & Advection & Advection & Advection & Advection & Advection & Advection & Advection \\
\hline & & & & & Generation & Generation & Generation & Generation & Generation \\
\hline & & & & & & Multispecies & Multispecies & Multispecies & Multispecies \\
\hline & & & & & & & $\begin{array}{l}\text { Cross- } \\
\text { species }\end{array}$ & Cross-species & Cross-species \\
\hline & & & & & & & & $\begin{array}{l}\text { Cross-section } \\
\text { capture }\end{array}$ & $\begin{array}{l}\text { Cross-section } \\
\text { capture }\end{array}$ \\
\hline
\end{tabular}


The progression problems capture incremental changes that begin with a simple once-through pipe model with the decay of a single radioisotope species and no advection. The problems become more complex by adding various behaviors to the fluid and relationships among the radioisotopes. The intent of this progression is to (1) enable a clearer understanding of where and how changes in models impact the accuracy and behavior of the numeric solution and (2) provide a verifiable process to construct complex MSR systems.

\subsubsection{Base TRANSFORM Model}

The TRANSFORM models applied in these problems have the same underlying foundation upon which additional capabilities or modified conditions are applied. The model uses the TRANSFORM generic pipe model, which provides a finite volume discretization by using a homogeneous equilibrium fluid model. Under this approach, mass, energy, momentum, and trace substances (e.g., radioactive species) are modeled, as well as the ability to incorporate additional physics (e.g., heat and trace mass transfer, other source/sink terms of interest). The base model that is used connects the pipe model to a mass flow and temperature boundary condition, which sets the condition of the fluid entering the pipe and a pressure boundary condition on the pipe outlet. This basic underlying model is captured in Figure 9. In each progression problem section, any modifications to the underlying model and driving behaviors (e.g., boundary conditions) are described. Additional details regarding the pipe model and treatment of trace substances can be found in Greenwood et al. [1]. The TRANSFORM models used to generate the data are included in the TRANSFORM library and can be found at the location of the public repository. ${ }^{2}$

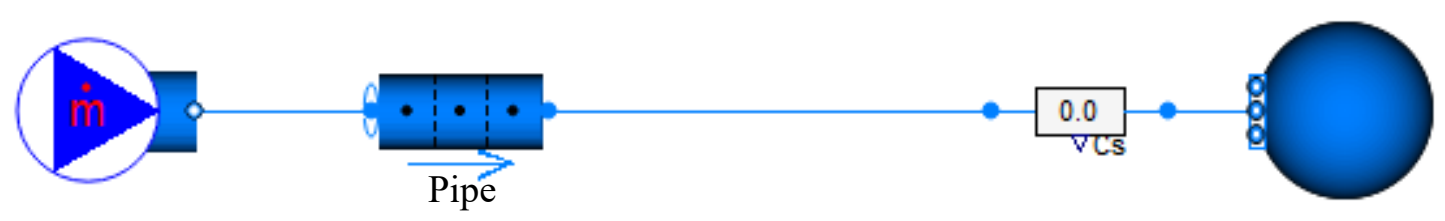

Figure 9. Base model for the demonstration of the species transport progression problems.

The model parameters that do not change between any of the benchmark problems are presented in Table 5 , where $T$ is temperature, $p$ is pressure, $C_{i}$ is the concentration of species $i, x$ is position, and $t$ is time.

${ }^{2}$ https://github.com/ORNL-Modelica/TRANSFORM-Library. 
Table 5. Base parameters of the TRANSFORM model that do not vary across progression problems.

\begin{tabular}{ccc}
\hline Component & Parameter & Value \\
\hline All & Fluid & FLiBe \\
\hline Inlet & $T\left({ }^{\circ} \mathrm{C}\right)$ & 20 \\
\hline Outlet & $p(\mathrm{~Pa})$ & $1 \mathrm{e} 5$ \\
\hline \multirow{3}{*}{ Pipe } & $\#$ of volumes & 10 \\
\cline { 2 - 3 } & Length $(\mathrm{m})$ & 0.1 \\
\cline { 2 - 3 } & Diameter $(\mathrm{m})$ & 0.01 \\
\hline \multirow{2}{*}{$\begin{array}{c}\text { Pipe initial } \\
\text { conditions }\end{array}$} & $\begin{array}{c}C_{i}(x, t=0) \\
(\# / m 3)\end{array}$ & 1,000 \\
\cline { 2 - 3 } & $T\left({ }^{\circ} \mathrm{C}\right)$ & 20 \\
\hline \multirow{3}{*}{$\begin{array}{c}\text { Simulation } \\
\text { settings }\end{array}$} & Solver & Dassl \\
\cline { 2 - 3 } & Tolerance & $1 \mathrm{e}-6$ \\
\cline { 2 - 3 } & Start time $(\mathrm{s})$ & 0 \\
\cline { 2 - 3 } & Stop time $(\mathrm{s})$ & 50 \\
& $\begin{array}{c}\text { Number of } \\
\text { intervals }\end{array}$ & 1,000 \\
\hline
\end{tabular}

\subsection{PROGRESSION PROBLEM DESCRIPTIONS}

This section briefly describes the progression problems modeled in the order shown in Table 3 . The problem description is then followed by an explanation of the TRANSFORM model with a focus on how the changes are made from the progression problem immediately before it. To provide an easier side-by-side comparison of the results, a combined presentation is given in Section 4.3.

\subsubsection{Problem 1: Single Species Decay}

This problem describes a stagnant fluid system with a uniform initial concentration of a radioactive species, which decays according to its half-life and without any interaction with neighboring fluid volumes. No additional source or sink terms beyond the decay term are present.

$$
\frac{d C_{i}(x, t)}{d t}=-\lambda_{i} C_{i}(x, t)
$$

\section{Problem 1 TRANSFORM Model}

The base model shown in Figure 9 is the model used in this problem in which the inlet flow rate of the primary fluid is set to a velocity $(v)$ of zero. The parameters specific to this problem are shown in Table 6 , where $\lambda_{i}$ is the decay constant of species $i$.

Table 6. Summary of the model parameters for progression problem 1.

\begin{tabular}{ccc}
\hline Component & Parameter & Value \\
\hline \multirow{3}{*}{ Inlet } & $v(\mathrm{~kg} / \mathrm{s})$ & 0 \\
\hline \multirow{3}{*}{ Pipe } & $\#$ of species & 1 \\
\cline { 2 - 3 } & $\lambda_{i}(1 / \mathrm{s})$ & 0.1 \\
\cline { 2 - 3 } & $i$ & 1 \\
\hline
\end{tabular}




\subsubsection{Problem 2: Advection}

This problem describes a flowing fluid system with a constant velocity and zero concentration fluid source boundary. All other aspects of the problem are identical to problem 1.

$$
\frac{d C_{i}(x, t)}{d t}+\nabla\left(v C_{i}(x, t)\right)=-\lambda_{i} C_{i}(x, t)
$$

\section{Problem 2 TRANSFORM Model}

The model used in this problem is identical to problem 1 except that the flow velocity was set as a constant and nonzero value, whereas the species inlet concentration was set to zero. Thus, the mass flow boundary condition was set according to Eq. (6) and Eq. (7), where $\rho(p, T)$ is the fluid density evaluated at the outlet pressure and inlet temperature (i.e., assuming an incompressible fluid), $A$ is the cross-sectional area of the pipe, and $d$ is the pipe diameter. The parameters specific to this problem are shown in Table 7.

$$
\begin{gathered}
m_{\text {flow }}=\rho\left(p_{\text {outlet }}, T_{\text {inlet }}\right) \cdot A \cdot v, \\
A=0.25 \cdot \pi d^{2} .
\end{gathered}
$$

Table 7. Summary of the model parameters for progression problem 2.

\begin{tabular}{ccc}
\hline Component & Parameter & Value \\
\hline \multirow{2}{*}{ Inlet } & $v(\mathrm{~kg} / \mathrm{s})$ & 0.02 \\
\cline { 2 - 3 } & $C_{i}(0, t)(\# / \mathrm{m} 3)$ & 0 \\
\hline
\end{tabular}

\subsubsection{Problem 3: Nonzero Boundary Condition}

This problem describes a flowing fluid system with a constant flow velocity and nonzero concentration at the fluid source boundary. All other aspects of the problem are identical to problem 2.

\section{Problem 3 TRANSFORM Model}

The model used in this problem is identical to problem 2 except that the species inlet concentration was set to a nonzero value. The parameters specific to this problem are shown in Table 8 .

Table 8. Summary of the model parameters for progression problem 3.

\begin{tabular}{ccc}
\hline Component & Parameter & Value \\
\hline Inlet & $C_{i}(0, t)(\# / \mathrm{m} 3)$ & 1,000 \\
\hline
\end{tabular}

\subsubsection{Problem 4: Periodic Boundary Condition}

This problem describes a flowing fluid system with a constant flow velocity and a boundary condition in which the concentration of the species leaving the system is equal to the concentration entering the system (i.e., a periodic boundary condition). All other aspects of the problem are identical to problem 3.

\section{Problem 4 TRANSFORM Model}

The model used in this problem is identical to problem 3 except that the species inlet concentration was set based on a periodic boundary condition by setting the measured species concentration at the outlet as the inlet concentration (Figure 10). The parameters specific to this problem are shown in Table 9. 


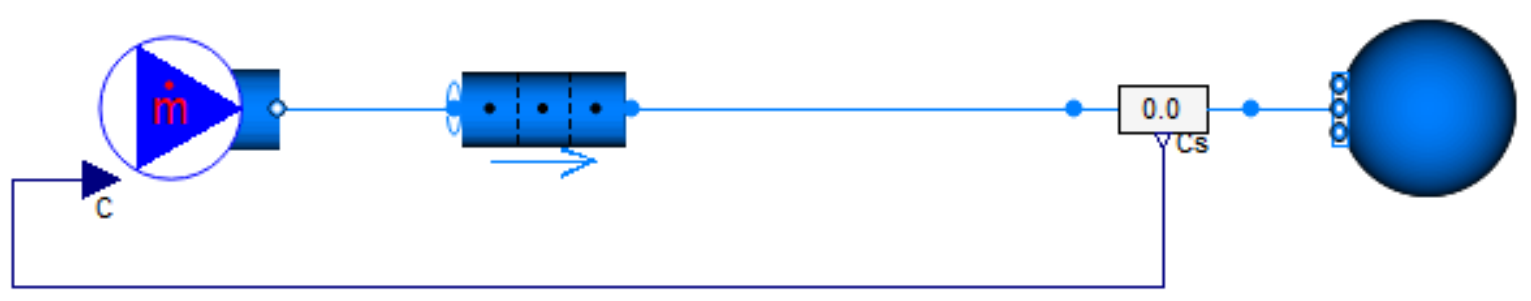

Figure 10. Base model for the periodic boundary condition problem.

Table 9. Summary of the model parameters for progression problem 4.

\begin{tabular}{ccc}
\hline Component & Parameter & Value \\
\hline Inlet & $C_{i}(\# / \mathrm{m} 3)$ & $C_{i}(0, t)=C_{i}($ end,$t)$ \\
\hline
\end{tabular}

\subsubsection{Problem 5: Species Generation}

This problem describes a flowing fluid system with a periodic boundary condition in which species are generated as a function of position in the pipe $(\psi)$. All other aspects of the problem are identical to problem 4.

$$
\frac{d C_{i}(x, t)}{d t}+\nabla\left(v C_{i}(x, t)\right)=\psi(x, t)-\lambda_{i} C_{i}(x, t)
$$

\section{Problem 5 TRANSFORM Model}

The model used in this problem is identical to problem 4 except that a species generation term is added to each volume. The parameters specific to this problem are shown in Table 10. The shape of the generation term is shown in Figure 11.

Table 10. Summary of the model parameters for progression problem 5.

\begin{tabular}{ccc}
\hline Component & Parameter & Value \\
\hline Pipe & $\psi(x, t)(\#)$ & $5 \cdot 10^{-4} \sin (\pi x)$ \\
\hline Generation &
\end{tabular}

Figure 11. Shape of generation $(\psi)$ term as a function of position.

\subsubsection{Problem 6: Multiple Species}

This problem is identical to problem 5 except that it has more than one radioactive species (i.e., $i>1)$. 


\section{Problem 6 TRANSFORM Model}

The model used in this problem is identical to problem 5 except that the species inlet concentration was set to a nonzero value. The parameters specific to this problem are shown in Table 11.

Table 11. Summary of the model parameters for progression problem 6.

\begin{tabular}{ccc}
\hline Component & Parameter & Value \\
\multirow{2}{*}{ Pipe } & $i$ & 4 \\
\cline { 2 - 3 } & $\lambda_{i}(1 / \mathrm{s})$ & $0.1,0.22,0.46,1.0$ \\
\hline
\end{tabular}

\subsubsection{Problem 7: Cross-Species Decay}

This problem is identical to problem 6 except for the addition of cross-species decay in which the decay of one species becomes the source of another species, where $\gamma$ is the parent-to-daughter transition matrix.

$$
\frac{d C_{i}(x, t)}{d t}+\nabla\left(v C_{i}(x, t)\right)=\psi(x, t)-\lambda_{i} C_{i}(x, t)+\sum_{j=1}^{i} \gamma_{i j} \lambda_{j} C_{j}(x, t)
$$

\section{Problem 7 TRANSFORM Model}

The model used in this problem is identical to problem 6 except for the addition of a parent-to-daughter transition term on the generation within each pipe node. In $\gamma$, the columns are the parents, and the rows are the daughters. The sum of each column should not be greater than one because it represents a "massbalance" of the decaying species. The parameters specific to this problem are shown in Table 12. For the specified $\gamma$ in the table, a brief description will help explain the results. This matrix indicates that all of species 1 (i.e., column 1) decays into species 2 (i.e., row 2). Similar logic was used for the decay of species 2 and 3. When species 4 decays, it simply disappears from the problem because whatever it decays into is not being tracked. The expected behavior in the results with the addition of the cross-species decay is that species 1 will not change because it remains identical to problem 6 . However, species 2, 3, and 4 will increase because they have an additional source term.

Table 12. Summary of the model parameters for progression problem 7.

\begin{tabular}{cccccc}
\hline Component & Parameter & \multicolumn{4}{c}{ Value } \\
\hline \multirow{3}{*}{ Inlet } & & $\gamma_{i j}$ & {$\left[\begin{array}{cccc}0.0 & 0.0 & 0.0 & 0.0 \\
1.0 & 0.0 & 0.0 & 0.0 \\
0.0 & 1.0 & 0.0 & 0.0 \\
0.0 & 0.0 & 1.0 & 0.0\end{array}\right]$} \\
\hline
\end{tabular}

\subsubsection{Problem 8: Cross-Section Capture}

This problem is identical to problem 7 except for an additional sink (i.e., negative generation) term that corresponds to the transmutation of a species due to some capture process, such as the capture of neutrons $(\epsilon)$.

$$
\frac{d C_{i}(x, t)}{d t}+\nabla\left(v C_{i}(x, t)\right)=\psi(x, t)-\lambda_{i} C_{i}(x, t)+\sum_{j=1}^{i} \gamma_{i j} \lambda_{j} C_{j}(x, t)-\epsilon(x, t) C_{i}(x, t) .
$$

\section{Problem 8 TRANSFORM Model}

The model used in this problem is identical to problem 7 except for the addition of a capture term, which destroys a species based on some profile. In this simplified problem, the behavior modeled is a form of 
decay in which the species is no longer tracked once it decays and the decay is an arbitrary shape function (i.e., skewed sine wave). The parameters specific to this problem are shown in Table 13. The shape of the capture term is shown in Figure 12.

Table 13. Summary of the model parameters for progression problem 8.

\begin{tabular}{ccc}
\hline Component & Parameter & Value \\
\hline Inlet & $\epsilon(x, t)$ & $0.1 \sum_{k=1}^{\infty} \frac{-\sin (k \pi[x+1])}{k}$ \\
\end{tabular}

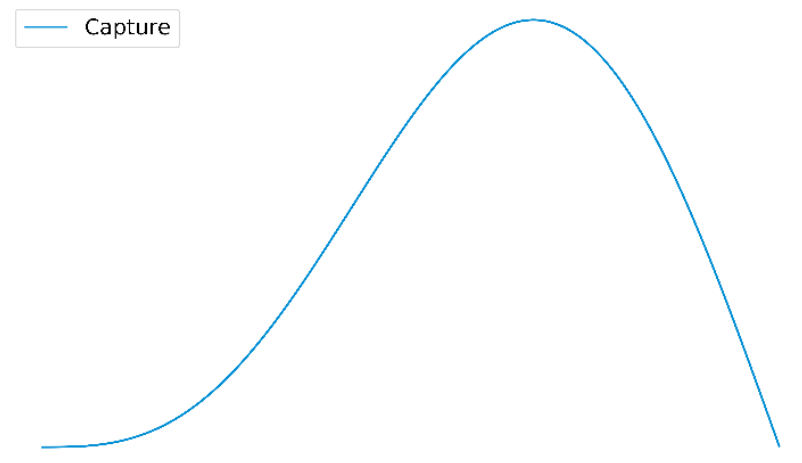

Figure 12. Shape of capture term $(\epsilon)$ as a function of position.

\subsubsection{Problem 9: Loop Geometry}

This problem is identical to problem 8 except for the addition of a "loop" section. This loop component adds a delay in the periodic boundary, allowing decay to occur before cycling back to the inlet.

\section{Problem 9 TRANSFORM Model}

The model used in this problem is identical to problem 8 except for the addition of another pipe model to represent the loop (Figure 13). This loop section has the same geometric dimensions as the original pipe and only participates in the decay of species, including cross-species, with no additional generation/sink terms. The parameters specific to this problem are shown in Table 14.

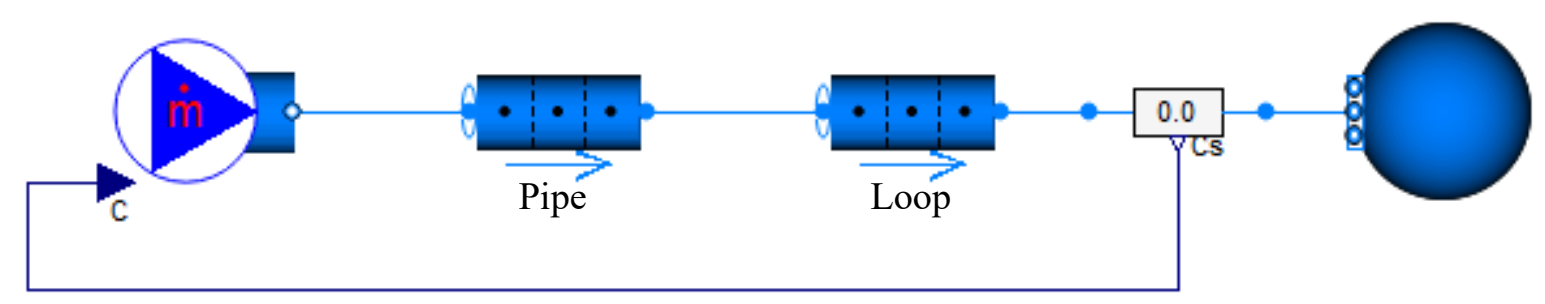

Figure 13. Base model for the periodic boundary condition with an additional loop element. 
Table 14. Summary of the model parameters for progression problem 9.

\begin{tabular}{ccc}
\hline Component & Parameter & Value \\
\hline \multirow{2}{*}{ Loop } & \# of volumes & 10 \\
\cline { 2 - 3 } & Length $(\mathrm{m})$ & 0.1 \\
\cline { 2 - 3 } Diameter $(\mathrm{m})$ & 0.01 \\
\hline $\begin{array}{c}\text { Loop initial } \\
\text { conditions }\end{array}$ & $\begin{array}{c}C_{i}(x, t=0) \\
(\# / \mathrm{m} 3)\end{array}$ & 0 \\
\cline { 2 - 3 } & $T\left({ }^{\circ} \mathrm{C}\right)$ & 20 \\
\hline
\end{tabular}

\subsection{MODELING RESULTS}

Figure 14 presents the concentration of the radioactive species as a function of time at discrete time intervals for problems 1-5. However, Figure 15 - Figure 18 present a similar plot for each of the four species because problems 6-9 include multiple species. The "inlet" of the pipe is at 0 , and the "outlet" is at 1 . However, the data are plotted from 0.05 to 0.95 as the fluid volumes because the state calculations occur at the volume centers. Table 15 provides a simplified summary of the difference between each problem and the one before it (i.e., the highlighted portions of Table 3). A discussion of the presented figures with an emphasis on the differences between the results is presented as follows. As mentioned previously, discussion on the solution accuracy will be included in a separate study once the progression problem publication with data for comparison are available. The simulation settings and high-level simulations statistics for these simulations are provided in Table 16.

Table 15. Summary of the difference between progression problems.

\begin{tabular}{cl}
\hline Problem & Difference $^{*}$ \\
\hline 1 & N/A \\
\hline 2 & Advection \\
\hline 3 & Constant, nonzero boundary condition (BC) \\
\hline 4 & Periodic BC \\
\hline 5 & Generation \\
\hline 6 & Multispecies \\
\hline 7 & Cross-species \\
\hline 8 & Cross section capture \\
\hline 9 & Loop geometry \\
\hline *Indicates the difference from the problem numerically before the current cell. For \\
example, problem 2 modifies problem 1 with advection. \\
\hline
\end{tabular}

Table 16. Simulation summary for the progression problems.

\begin{tabular}{lc}
\hline Parameter & Value \\
\hline Simulation time (s) & 40 \\
\hline Real time (s) Prob. 1-9 & $\begin{array}{c}0.075,0.114,0.115,0.162,0.159, \\
\end{array}$ \\
\hline Solver & Dassl \\
\hline Solution tolerance & $1.0 \mathrm{e}-6$ \\
\hline Equations Prob. 1-9 & 2,$076 ; 2,076 ; 2,076 ; 2,077 ; 2,077 ;$ \\
& 2,$923 ; 2,923 ; 2,923 ; 5,666$ \\
\hline
\end{tabular}


Problem 1
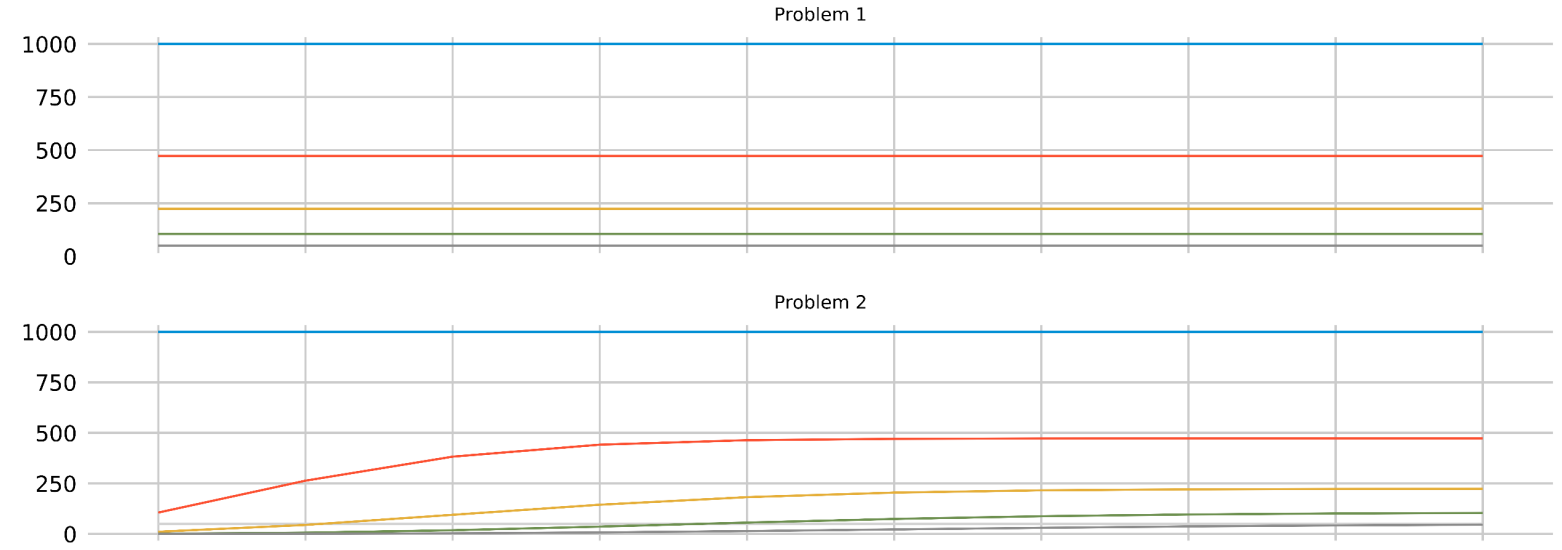

Problem 3

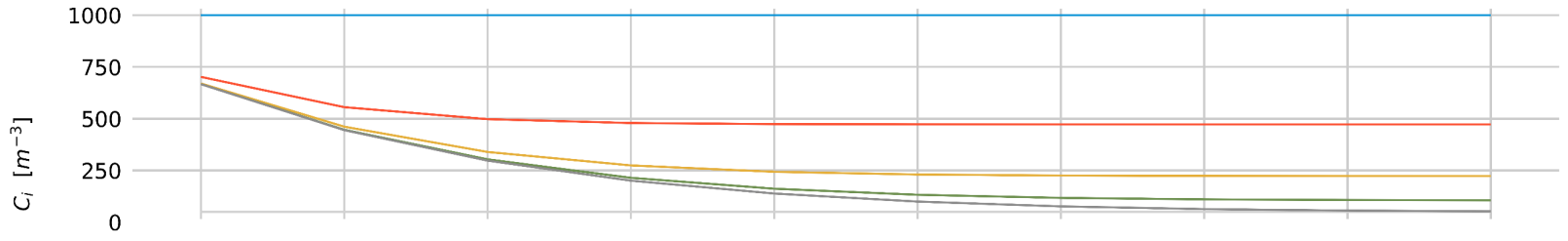

Problem 4
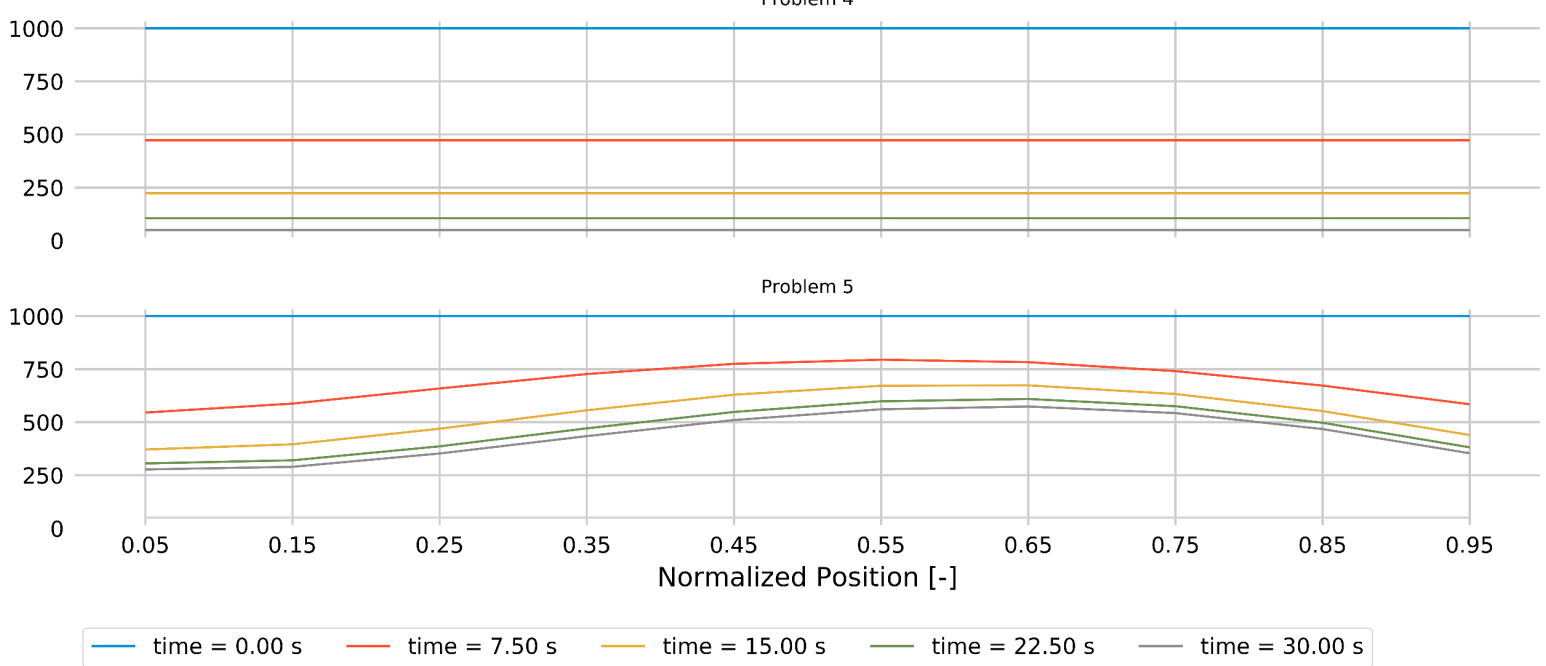

Figure 14. Concentration of species $i=1$ as a function of position at discrete time steps for problems $1-5$. 


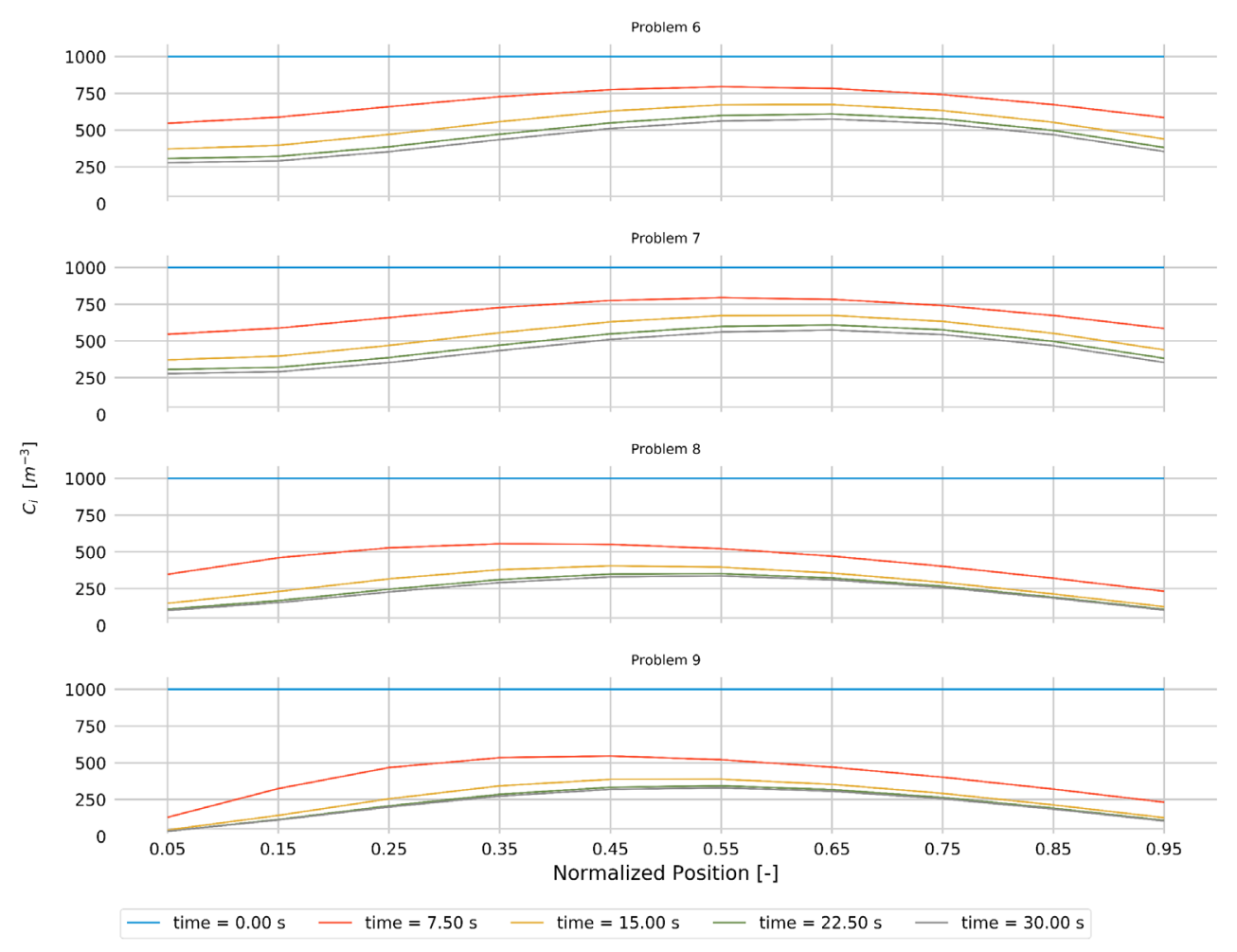

Figure 15. Concentration of species $i=1$ as a function of position at discrete time steps for problems 6-9.
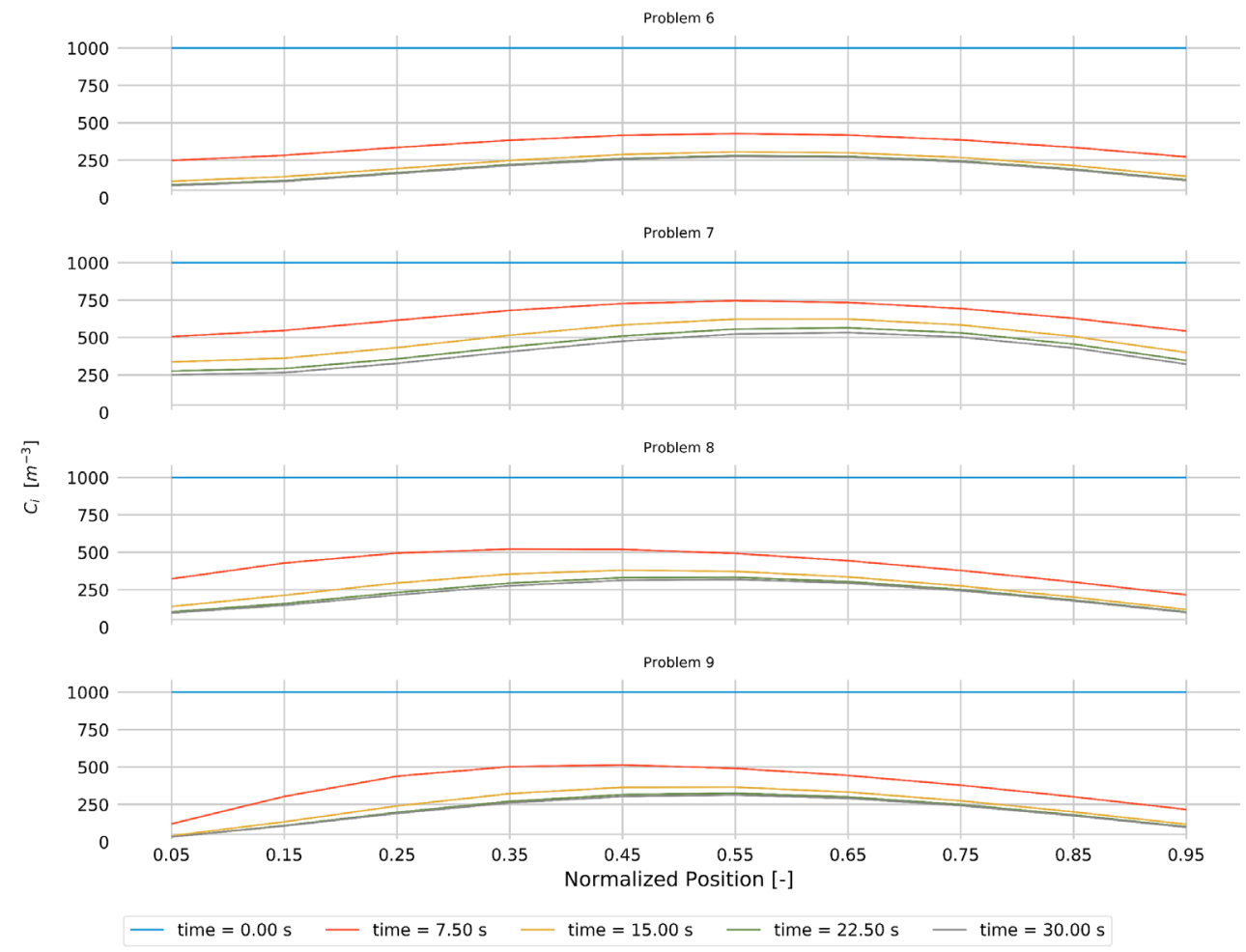

Figure 16. Concentration of species $i=2$ as a function of position at discrete time steps for problems 6-9. 


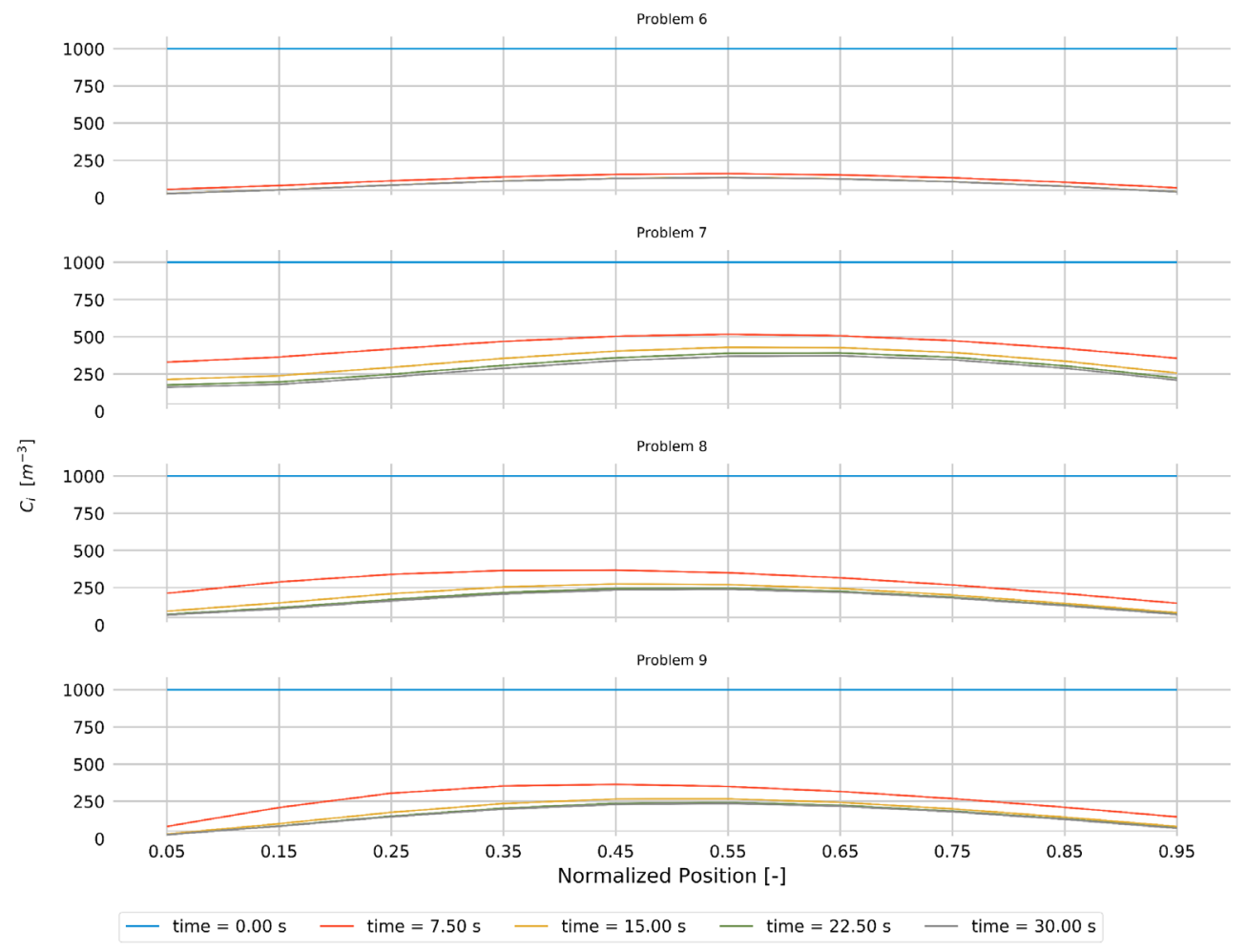

Figure 17. Concentration of species $i=3$ as a function of position at discrete time steps for problems 6-9.
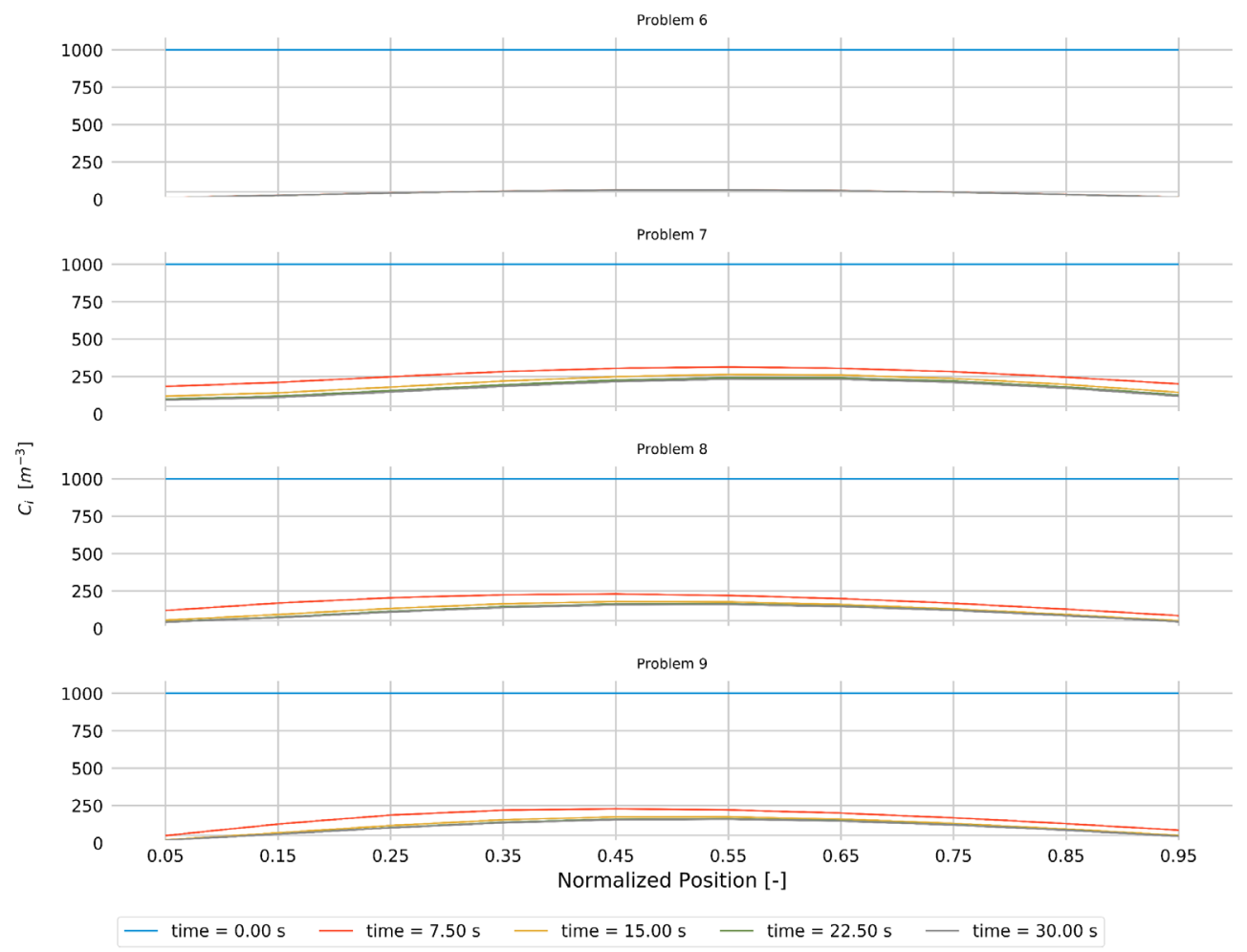

Figure 18. Concentration of species $i=4$ as a function of position at discrete time steps for problems 6-9. 


\subsubsection{Problems 1-5}

This set of problems focuses on the gradual inclusion of behaviors that are present in the operation of an MSR with a focus on only a single species (Figure 14). Problem 1 provides a uniform response at all positions as a function of time due to the lack of flowing salt. Therefore, no drift effect occurs since no radioactive species leave their volume. Adding flowing fluid with a constant zero species inlet in problem 2 causes an accelerated approach to eliminate the species, starting with the inlet of the pipe and then gradually propagating through the pipe over time. The transition to a nonzero boundary condition in problem 3 shifts the minimum value up while retaining a wave effect due to advection. The periodic boundary condition of problem 4 returns the same results as problem 1. Given there are no other delays in this simple model, this behavior is expected because all cells are equivalent again since the species that leaves one volume enters the next volume at the same concentration that it left. A generation source for species in problem 5 imparts a shape to the results according to the source generation shape, although the peak of the sinusoid is skewed slightly downstream due to advection. These behaviors align with the expectations and provide a first test that the model is correctly representing the physics of an MSR.

\subsubsection{Problems 6-9}

This set of problems focuses on adding behaviors that are related to multiple radioactive species (Figure 15 - Figure 18). Species 1 for problem 6 provides results identical to those in problem 5, and the only difference between the two problems is the extension of the number of species from one to four. Continuing with species 1 , problem 7 is identical to problem 6 because no cross-species generation is specified for this species. Problem 8 shifts the shape based on the capture shape, shifting the maximum near the inlet instead of the outlet. Problem 9 then reduces the inlet concentration due to the increased residence time, allowing species to decay before reentering the pipe. Species 2, 3, and 4 have progressively faster decay rates. Thus, the species exhibit the same behaviors as species 1 . However, as the decay rates increase, the impact of advection diminishes because the species rapidly disappear before traveling far from their original location. Problem 8 for species 2-4 is also slightly higher than its result in problem 7 due to the decay of the previous species being a source term, as described in the problem 8 description.

\subsection{PROGRESSION PROBLEM SUMMARY}

The progression problems presented in this section provide a systematic basis for building an understanding of how radioisotopes move in an MSR system and confidence in the simulation results. This set of problems will be expanded and verified against analytical and other numerical solutions in future work. These results are directly related to understanding mass accountancy because the previously discussed liquid-gas phase modeling will fit into the next set of progression problems, which demonstrate the impact of integrating a dynamic speciation capability. 


\section{CONCLUSION}

Mass accountancy is a critical aspect of MSRs. The nature of a dissolved fuel requires ways to track the salt composition with specific focus on radioactive fission products and mass-based approaches. This mass accountancy need extends beyond the primary reactor loop to all supporting systems to which radioactive species could travel during normal and off-normal condition such as additional heat transfer loops and offgas systems. This report presents a discussion of a molten salt database, which is being leveraged to develop one such mass accountancy tool, TRANSFORM. To advance the understanding of the how and why to couple these capabilities, a demonstration model was created and simulated. This work determined that a tight coupling of the two tools is required to achieve the level of detail for mass accountancy desired for many critical MSR studies. Another key outcome was the identification of a need for progressive benchmark problems to provide confidence in the results returned from simulations. Since development of related benchmark problems is occurring, this work leveraged early versions of benchmark activities and developed a set of example models that will be verified in the future as those efforts mature. 


\section{ACKNOWELEDGMENTS}

This research was funded by DOE's Office of Advanced Reactor Technology Molten Salt Reactor Campaign. This manuscript was authored by UT-Battelle LLC under contract DE-AC05-00OR22725 with DOE. 


\section{REFERENCES}

1. Greenwood, M.S., Betzler, B.R., Qualls, A.L., Yoo, J., Rabiti, C.: Demonstration of the Advanced Dynamic System Modeling Tool TRANSFORM in a Molten Salt Reactor Application via a Model of the Molten Salt Demonstration Reactor. Nucl. Technol. 1-27 (2019). https://doi.org/10.1080/00295450.2019.1627124

2. Greenwood, M.S.: TRANSFORM - A Vision for Modern Advanced Reactor System-Level Modeling and Simulation Using Modelica. In: Proceeding of the American Nuclear Society., Virtual (2020)

3. The CALPHAD method - Thermo-Calc Software, https://www.thermocalc.com/productsservices/databases/the-calphad-methodology/

4. Besmann, T.M., Ard, J., Utlak, S. (ORCID:0000000188340760), Mcmurray, J.W. (ORCID:0000000151113054), Lefebvre, R.A. (ORCID:0000000203532307): Status of the salt thermochemical database. Oak Ridge National Lab. (ORNL), Oak Ridge, TN (United States) (2019)

5. Olander, D.R.: Fundamental aspects of nuclear reactor fuel elements. California Univ., Berkeley (USA). Dept. of Nuclear Engineering (1976)

6. Nellis, G., Klein, S.A.: Heat Transfer. Cambridge Univ. Press, Cambridge (2012)

7. Bale, C.W., Bélisle, E., Chartrand, P., Decterov, S.A., Eriksson, G., Gheribi, A.E., Hack, K., Jung, I.H., Kang, Y.-B., Melançon, J., Pelton, A.D., Petersen, S., Robelin, C., Sangster, J., Spencer, P., Van Ende, M.-A.: Reprint of: FactSage thermochemical software and databases, 2010-2016. Calphad. 55, 1-19 (2016). https://doi.org/10.1016/j.calphad.2016.07.004

8. Graham, A., Taylor, Z., Collins, B.S., Greenwood, M.S.: Progression Problems for Validation of Species Transport Calculations for Molten Salt Reactors. In: In Review. American Nuclear Society, Virtual (2021) 